(NAS 1.20:168994) DISA CCNCEAThaTOhS FCa

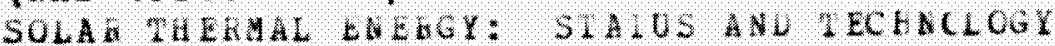

DEVELUPHENI (Jet FLOflisich Lat.) 69 P

HC $\mathrm{A0} 4 / \mathrm{AF}$ AOO

CSCL 10A

$1 \mathrm{ncL}$ as

$03 / 44 \quad 27903$

\title{
Dish Concentrators for Solar Thermal Energy: Status and Technology Development
}

L. D. Jaffe

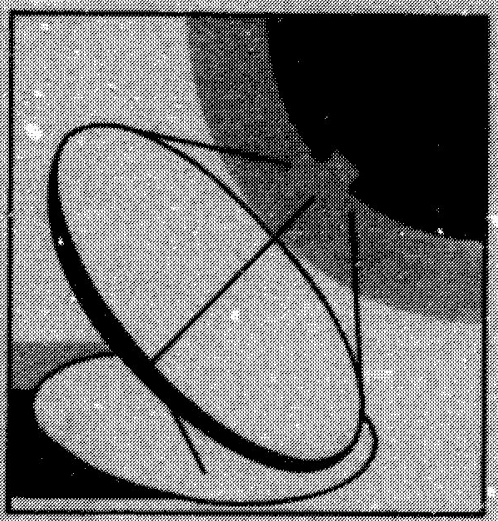

vanuary 1.1002

Prepared for

U.S. Department of Energy

Through an Agreement with

Nationa Aeronautics and Space Administration

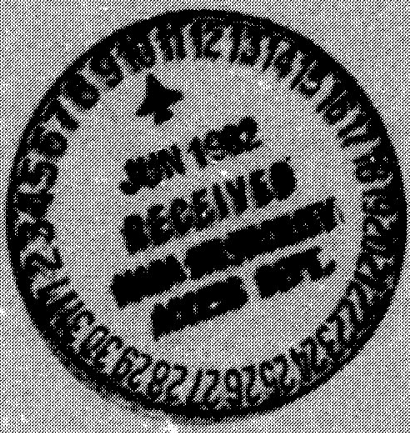

by

Jet Propulision Laboratory

California institute of Technology

Pasadena, Calitornia

(JPL. PUELICATION 81-43) 


\section{Dish Concentrators for Solar Thermal Energy: Status and Technology Development}

L. D. Jaffe

January 1, 1982

Prepared for

U.S. Department of Energy

Through an Agreement with National Aeronautics and Space Administration

by

Jet Propulsion Laboratory

California Institute of Technology

Pasadena, California

(JPL PUBLICAT:ON 81.43) 
Prepared by the Jet Propulsion Laboratory, California Institute of Technology, for the U.S. Department of Energy through an agrement with the National Aeronautics and Space Administration.

The JPL Solar Thermal Power Systems Project is sponsored by the U.S Department of Energy and is part of the Solar Thermal Program lo develop low. cost solar thermal and electric power plants.

This report was prepared as an account of work sponsored by an agency of the United States Government. Neither the United States Government nor any azency thereof, nor any of their employees, makes any warranty, express or implied, or assumes any legal liability or responsibility for the acruracy. completeness, or usefulness of any information, apparatus, product, or process disclosed, or represents that its use would not infringe privately owned rights.

Reference herein to any specific commercial product, process, or service by trade name, irademark, manufacturet. or otherwise, does not necessarily constitute or imply its endorsement, recommendation, or favoring by the Uniled States Government or any agency thereof. The views and opinions of authors expressed herein do not necessarily state or reflect those of the United States Government or any agency thereof. 
A wide variety of point-focusing concentrators are under consideration for solar thermal energy use. They are reviewed briefly in this paper. These concentrators differ in such characteristics as optical configuration, optical materials, structure for support of the optical elements and of the receiver, mount, foundation, drive, and controls.

Point-focusing concentrators need good optical efficiency and, especially for hlgh-temperature applications, high geometric concentration ratio. Most important for the ruture, however, is low installed cost and low lifetime cost. Critical cost contributors for quentity production are the cost of materials and the cost of installation labor.

Technology development for concentrators is needed in such areas as optical materials, establishment of design wind speeds and wind loads (including array interactions), structural configurations, stability of structural polymeric and forest-product materials during environmental exposure, and cleaning and maintenance of optical surfaces. Especially needed is field testing of complete collectors, $1 . e .$, concentrators with receivers and controls. 


\section{ACKNOKLEDGENT}

I thank the concentrator design organizations mentioned for the data they supplied. William Revere, William Carley, Edwin Deinison, William Owen, Brian Beveridge, and John Lucas of JPL; Roger Bedard, Jr., of Acurex Corporation; and William Dampier of Omnium-G Company provided helpful information.

Responsibility for the accuracy of the information is, however, the author's.

This report was published by the Jet Propulsion Laboratory through NASA TASK RD-152, ANENDIENT 327 and was sponsored by the U.S. Department of Energy under Interagency Agreement DE-AT04-81AL16228.

\section{FOREWORD}

A brief version of this document has been published as reprint AIAA-81-2530 by the American Institute of Aeronautics and Astronautics, 2nd Terrestrial Energy Systems Conference, December 1-3, 1981, Colorado Springs, Colorado. 
CONTENTS

EXECUT IVE SUMMAY . . . . . . . . . . . . . . . . . . 1

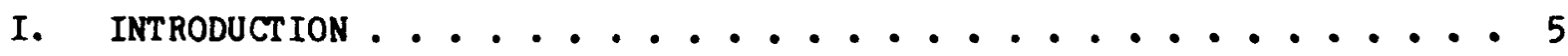

II. CONCENTRATOR DESIGNS AND DEVELOPMENT . . . . . . . . . . . 7

A. OPTICAL CONFIGURATIONS .................. 7

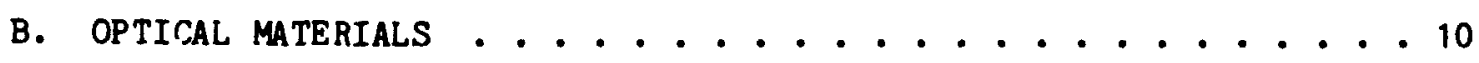

C. MIRROR/LENS SUPPORT STRUCTURE ................ 11

D. RECEIVER SUPPORT ............................ 11

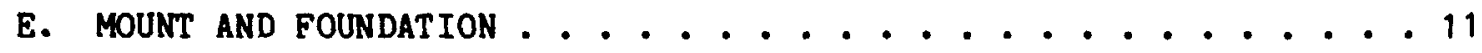

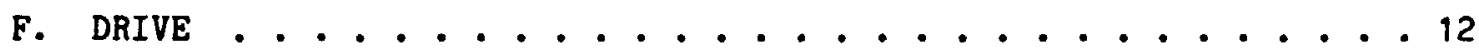

G. CONTROLS . . . . . . . . . . . . . . 12

H. ENCLOSURE .......................... 13

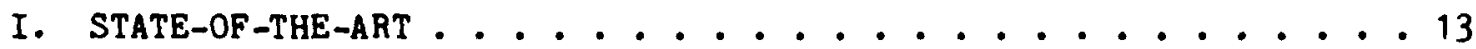

III. CONCENTRATOR PERFORMANCE AND COST ..................... 41

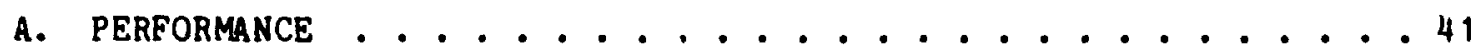

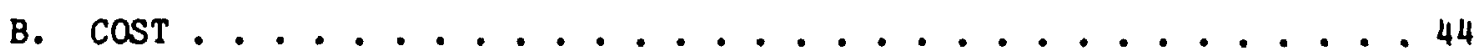

IV. TECHNOLOGY DEVELOPMENT . . . . . . . . . . . . . . 51

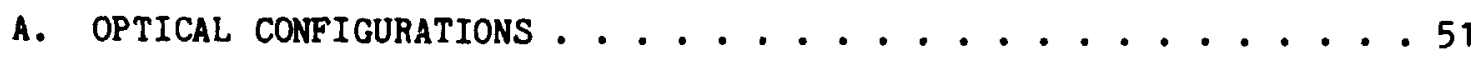

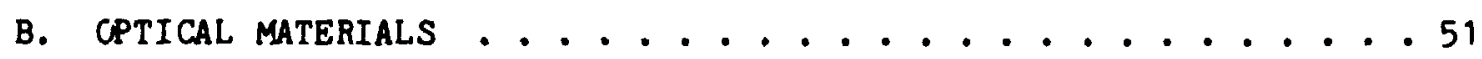
C. WIND LOADS AND AERODYNAMICS ... . . . . . . . . . . . 51
D. ENVIRONMENTAL REQUIREMENTS - PRECIPITATION, SAND, AND SEISMIC • 52
E. STRUCTURAL CONFIGURATIONS ............... 53

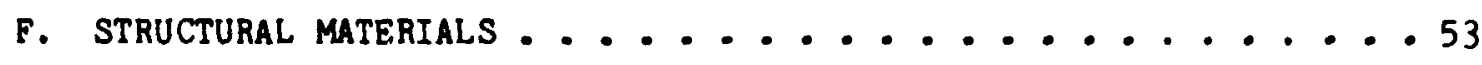
G. ENCL@URES . . . . . . . . . . . . . . . . 53 


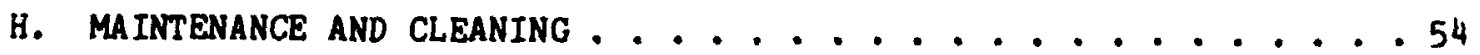

I. TECHNOLOGY DEVEL OPMENT UNDERWAY ............. 54

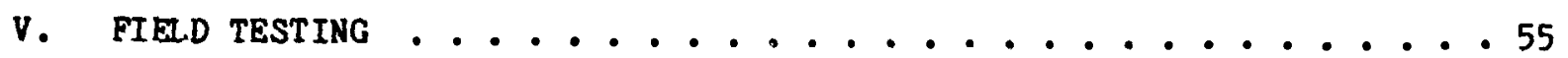

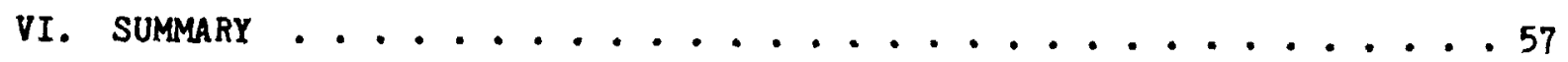

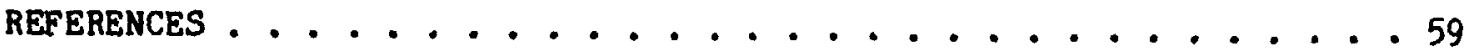




\section{Figures}

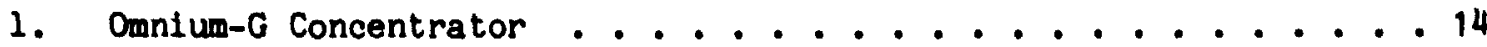

2. Shenandoah Concentrator .............. 15

3. General Electric Concentrator .............. 16

4. Acurex Concentrator ................. 17

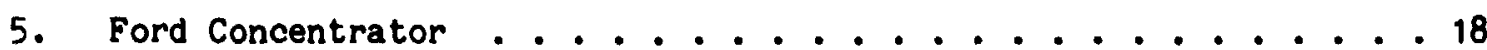

6. Boeing Concentrator ............... 19

7. JPL Heliostat Adaptation ............... 20

8. E-Systems/JPL Test Bed Concentrator ............. 21

9. Raytheon Concentrator ............... 22

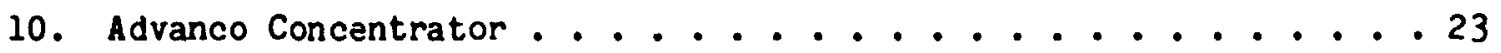

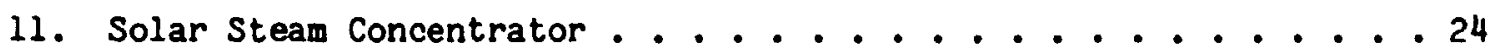

12. Sol-Trac Concentrator .................... 25

13. University of Arizona Concentrator . . . . . . . . . 26

14. Power Kinetics Concentrator ............... 27

15. Sketch of Fresnel Mirror Concentrator . . . . . . . . 28

16. Sun Power Fresnel Concentrator . . . . . . . . . . . 29

17. Sketch of Fresnel Lens Concentrator . . . . . . . . . 30

18. E-Systems Fresnel Concentrator . . . . . . . . . . 31

19. Compound Concentrator Using Secondary Concentrator to Fold Optical Path (Cassegrainian Configuration) ....... 32

20. Compound Concentrator Using Secondary Concentrator to Increase

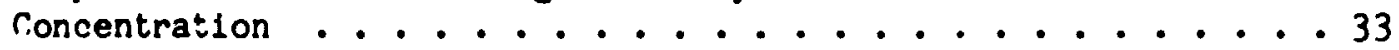

21. Sanders Recelver with Secondary Concentrator . . . . . . . 34

22. University of Chicago Secondary Concentrator . . . . . . . 35

23. Crosbyton Concentrator: Fixed Spherical Bowl ....... 36

24. Boelng Enclosed Concentrator .............. . . 37 
25. Transolar Concentrator ..................... 38

26. Summit Industries Concentrator . . . . . . . . . . 39

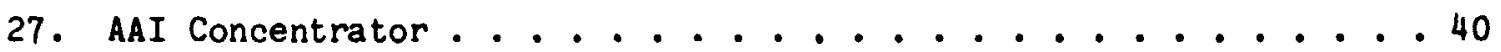

28. Effect of Geometric Concentration Ratio and Receiver Temperature on Collector and System Efficiency

(Idealized System) ................. . . 42

29. System Efficiency Versus Receiver Temperature with Engines of Differing Characteristics . . . . . . . . . . . 43

30. Geometric Concentration Ratio Attainable for Paraboloidal Mirror as a Function of Slope Error and Intercept Factor . . . . 45

31. Distribution of Capital Costs for Solar Thermal Power Plant (Projected) ............... . 46

32. Effects of Concentrator Cost and Optical Efriciency Upon Cost of Electrinity Produced (Projected) . . . . . . . . 48

33. Effect of Geometric Concentration Ratio Upon Cost of Electricity Produced for Various Receiver Temperatures

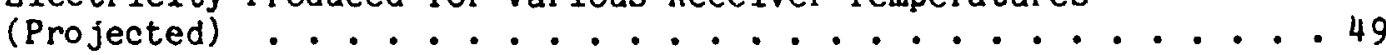

1. Summary Characteristics of Some Point-Focusing Concentrators . . 8 


\section{EXECUT IVE SUMMARY}

Point-focusing solar concentrators (dish concentrators) provide an efficient means of gathering solar energy for conversion to high-temperature heat. 'his heat may either be used directly or converted further to mechanlcal work or to electricity. This paper (1) outlines basic elements in which concentrator designs differ and the cholces possible for each element; (2) illustrates these choices with examples which constitute a survey of current dish concentrator concepts; (3) summarizes some cost targets for dish concentrators and the factors that af fect concentrator costs; (4) summarizes dish performance characteristics, the factors trat affect them, and some relationships between performance and cost; and (5) points out technical developments needed to attain desired cost and performance.

\section{CONCENTRATOR DESIGNS}

Table 1 (page 8) is a summary of the characteristics of some current U.S. dish concentrator concefts; the concentrators are pictured in Figures 1 through 27 (pages 14 thruugh 40). As the table indicates, concentrators differ in optical configuration, optical materials, the structure supporting the optical elements themselves, the mount and foundation, drive mechanism, controls, and the presence or absence of an enciosure.

The conventional optical configuration for a dish concentratur is a paraboloidal mirror. The paraboloidal shape, however, may be segmented into a number of large paraboloidal panels, into smaller spherical facets, or, if the facet: are smaller than the desired receiver aperture, into small flat facets. Segmented mirrors need not retain the overall paraboloidal shape: If rroperly oriented, the mirror segments may be arranged in a flat or cylindrical geometry, forming a Fresnel mirror. Other variations are possible, such as thin cylindrical slats. A Fresnel lens may be used instead of a mirror. Also, a secondary concentrator may be added to fold the optical path or to increase the consentration. Choice amcng these configurations is a matter not only of optical performance but also of aerodynamic and structural performance, lifetime, system maintenance, and especially cost.

The conventional material is second-surface silver on glass. This material is reasonably durable and has good optical performance, but is somewhat expensive, heavy, and fragile. Sheet metal is more easily formed with double curvature, but 1ts optical properties are poorer and tend to degr de quiskly when the metal is exposed to the weather. Metallized polymeric films are inexpensive and have fair optical properties; their durability is still un. ain. For Fresnel lens concentrators, polymeric materials are an obvious choice, with polymethyl methacrylate the leading candidate.

To support the optical material, there is a large selection of structural designs and materials. The optical element need not be rigid; to save weight, it can le shaped by tension or by an air pressure differential. 
Dish concentrators require rotation about two axes to follow the sun. For rotation in elevation, the mirror or lens is often supported by bearings at the end of a diameter. Such elevation bearings are usually nlaced on wheeled pedestals which rotate in azimuth on a track. Concrete piers, often with a concrete ring, are the foundation. A cheaper approach may be to support the mirror with elevation and azimuth bearings near its center, mounted on a single post or tripod, which rests on a concrete pier or piers. Edge-mounting of the mirror is also possible.

Drive mechanisms may use electric or hydraulic drives through gears, chains, cables, linear actuators, or jacks. Performance, cost, reliability, and maintenance of each remain to be determined. Hydraulic drive may facilitate storage of energy for emergency stow or to drive off the sun if electrical power fails.

To point the concentrator at the sun, analog or digital controls, either open- or closed-10op, may be used. Most common is tracking using sur sensors, together with a stored enhemeris for acquisition and for cloudy intervals.

In most designs the concentrator is in the open, but it may be enclosed in a transparent enclosure to reduce the high structural loads due to wind and other effects of weather. The enclosure may be supported on a framework or by differential air pressure. Whether the advantages of an enclosure compensate for the optical loss at the enclosure is a question.

A survey of current dish concepts (Table 1, Figures 1-27) Indicates that most of the alternatives mentioned above are being tried. Emphasis is on attaining low lifetime cost in mass-production quantities, together with adequate performance at the receiver operating temerature. For electrical power, receiver temperatures of 400 to $900^{\circ} \mathrm{C}\left(700\right.$ to $\left.1700^{\circ} \mathrm{F}\right)$ are of primary interest, with some consideration of higher temperatures in the future. For process heat, the temperature range is wider.

\section{CONCENTRATOR COSTS}

System studies indicate that concentrators generally will be the largest single cost element in solar thermal systems. Concentrator cost is often expressed in $\$ / \mathrm{m}^{2}$ of concentrator area. In using such figures it is important to identify the year to which the dollars refer and whether they represent manufacturer's cost, f.o.b. price, installed cost, cost with lifetime cleaning and maintenanse, etc.

In mass production, the cost of materials is likely to be the most important contributor to concentrator price. Thus, there is much incentive to minimize weight and to use inexpensive materlals. In addition to concentrator price, the user must consider transportation, land, site preparation, foundation, installation, and architect-engineer costs. Foundation and installation work, utilizing field labor, can be especially expensive. After installation, there will be costs for cleaning, waintenance, and replacement. Over a desired lifetime of 30 years (for sowe applications) these costs can const itute a large fraction of lifetime cost. 
A target of $100 \mathrm{mill} / \mathrm{s} / \mathrm{kW}-\mathrm{h}$ ( $1 \mathrm{n} 1980$ dollars) has beer suggested for electricity produced by solar thermal electric systems for the mid-1990's, on the basis of both competition from fuel-fired systems and the solar power costs considered attainable with mass production. An examination of system costs suggests that an initial installed price of $\$ 90-150 / \mathrm{m}^{2}$ ( 1980 dollars) for the concentrators would be consistent with the electricity cost target if concentrator performance and lifetime were good.

\section{CONCENTRATOR PERFORMANCE}

Performance of a solar concentrator may be expressed in terms of three quantities: (a) optical efficiency and (b) geometric concentration ratio at (c) a given intercept factor. There is a trade-off between optical efficiency and geometric concentration ratio, through the intercept factor. Typical optical efficiencies are 0.8 to 0.95 ; typical intercept factors are greater than 0.9 ; and typical geometric concentration ratios for dish concentrators are 100 to 3000 . The geometric concentration ratio needed depends upon the temperature to be generated. Low geometric concentration ratios may be quite satisfactory for low temperature use, but will lead to low system efficiency at high temperatures. The temperature needed depends upon the application: If mechanical work or electricity is required, high operating temperatures will be desirable for efficient conversion of heat to work and electricity, and a high geometric concentration ratio, therefore, will be preferred.

The geometric concentration ratio attainable at a given intercept factor depends principally upon the focal ratio, slope errors, specularity, and pointing error of the concentrator optical surface. Slope errors of the surface (deviations from the ideal shape) have a strong effect upon the attainable concentration and may be introduced during design, during installation, by manufacturing deviations, by structural or thermal deflections, and by distortion due to aging or weathering.

The efficiency of a solar thernal power system, the cost of the electricity or heat produced, and the capital cost of the equipment are strongly influenced by concentrator performance. For a given plant output, more concentrator area will be needed if the concentrator performance is low. Therefore, a reduction in cost per square meter of concentrator area accompanied by a significant decrease in concentrator performance may increase the required capital investment and the cost of the electricity produced. A concentrator needs to have not only low cost per unit area but also performance adequate for the application. For some applications, an optical efficiency of 0.90 to 0.93 with a geometric concentration ratio of 2000-2500, at an intercept factor of 0.98 , is suggested as a target.

\section{TECHNOLOGY DEVELOPMENT AND TESTING}

The state-of-the-art is indicated by the concepts shown in Table 1 and the illustrations of various concentrators. To obtain concentrators with low cost and good performance, effort is needed to develop ind improve concentrator concepts and designs, manufacturing and installation me;hods, and maintenance methods. Also needed are technology development and testing. 
O.se area in which development is needed is the conception and analysis of optical configurations that may lead to lower cost or better performance, taking into account the imperfections that occur in all real concentrators. Another important area is that of optical materials: improvements in mirror reflectivity, increase in durability, and decrease in cost. Examination and testing of polymeric materials for mirror substrates and for lenses is especially desirable, with attention to optical performance, durability and stability, and formability of both bulk materials and films. Transparent protective coatings are also needed.

The governing loads on concentrator structures tend to be wind loads. Work is needed on selection of the wind conditions to be used for design and on the aerodynamics of concentrators. New structural configurations need to be examined for lower cost. Dynamic behavior of both new and conventional designs under wind loading should be examined. Polymeric materials and forest products may offer possibilities for reducing the cost of concentrator structures, but testing is needed to determine their dimensional and mechanical stability for the long outdoor exposures which concentrators must withstand. A different approach is the development of thin enclosures to protect concentrators. For this approach, optical and mechanical properties, durability, low cost, and ease of fabrication of the enclosure material have to be established.

\section{FIELD TESTING}

Table 1 shows that many dish concentrator concepts exist on paper, but few have been built and tested. Construction, field testing, and evaluation of concentrators are crucial to further progress. Included in the evaluation should be concentrator performance before and after several years' exposure to the weather. 


\section{SECTION I}

\section{INTRODUCTION}

Point-focusing solar concentracors (dish concentrators) provide an efficient and $n$,nvenient means of gathering solar energy for conversion to high-temperature heat. This heat may either be used directly or converted further for mechanical work or to electricity.

This paper outli es basic design elements of dish concentrators that may differ from concentrator to concentrator, indicates some of the choices possible for each element, and illustrates these choices with examples selected from current concentrator design concepts. These examples also constitute a survey of present-day U.S. dish concentrators showing the state-of-the-art. Next, the paper summarizes some cost targets for dish conceritrators and the factors that determine the costs, dish performance characteristics and some factors that affect them, and certain relationships between cost and performance. Finaily, this paper points out some technical developments needed to attain desired cost and performance. 



\title{
HRECEDING PAGE BLANK NOT FILMED
}

\author{
SECTION II \\ CONCENTRATOR DESIGNS AND DEVELOPMENT
}

\begin{abstract}
A wide variety of dish concentrators have been proposed, and a fair number have been built. They differ in such characteristics as optical configuration, optical material, structure and material supporting the optical element, receiver support, mount, foundation, drive, controls, and use of enclosure. In this section these characteristics are outlined and discussed briefly, with illustrations and examples chosen primarily from concentrators being developed under tra Solar Thermal Power Systems Project at the Jet Propulsion Laboratory, California Institute of Technology. This project is part of the overall program of the Solar Thermal Technology Division of the U.S. Department of Energy and is sponsored by that division through an agreement with the National Aeronautics and Space Administration.
\end{abstract}

Earlier work on the project is discussed in References 1 through 6. Principal characteristics of the concentrators mentioned in this paper are summarized in Table 1.

\section{A. OPTICAL CONFIGURATIONS}

A point-focusing dish may use the conventional paraboloidal mirror, or individual reflecting petals or facets which approximate a paraboloidal surface. If a fairly small number of petals or facets are used, so that they are not much smaller than the dish itself, they will need to be paraboloidal to provide a good geometric concentration ratio (Figs. 1-7). (Concentration ratio is discussed below.) If many small facets are used, high concentration can be obtained with spherical facets (Figs. 8-11). If the facets are smaller than the receiver aperture, good concentration ratios can be obtained with flat facets (Figs. 12-13). Other variations are possible, such as narrow slats: flat in one direction, cylindrically curved in another (Fig. 14).

The distinction between faceted and Fresnel mirrors is not sharp. With properly oriented facets, there is no need to maintain the overall paraboloidal shape. The facets can be placed on a flat support forming the classical Fresnel mirror (Figs. 12, 15 and Ref. 41), on a support of flat segments (Fig. 13), on a cylindrical support (Fig. 16), etc. This may have structural, aerodynamic, cost, or other advantages. A disadvantage is that each facet tends to block the light to or from adjacent facets (Fig. 15) unless gaps are left between them. Such gaps reduce the effective aperture of the concentrator.

A concentrator may utilize a lens rather than a mirror. To minimize the thickness, optical absorption, and weight, a Fresnel lens is needed (Figs. 17, 18 and Ref. 42). Lens collectors place the receiver (and power conversion equipment located with the receiver) closer to the ground during operation than do reflectors; this may be advantageous for maintenance. Also, in a lens concentrator, the receiver and its supports do not block the sunlight. The performance of some Fresnel lenses is much less sensitive to slope errors than that of mirrors. On the other hand, lenses have shromatic aberration. Also, lenses are $11 \mathrm{mited}$ to a somewhat longer focal ratio (focal length/diameter) than mirrors; this may lead to longer and heavier recelver supports and to a higher mount to provide ground clearance. 


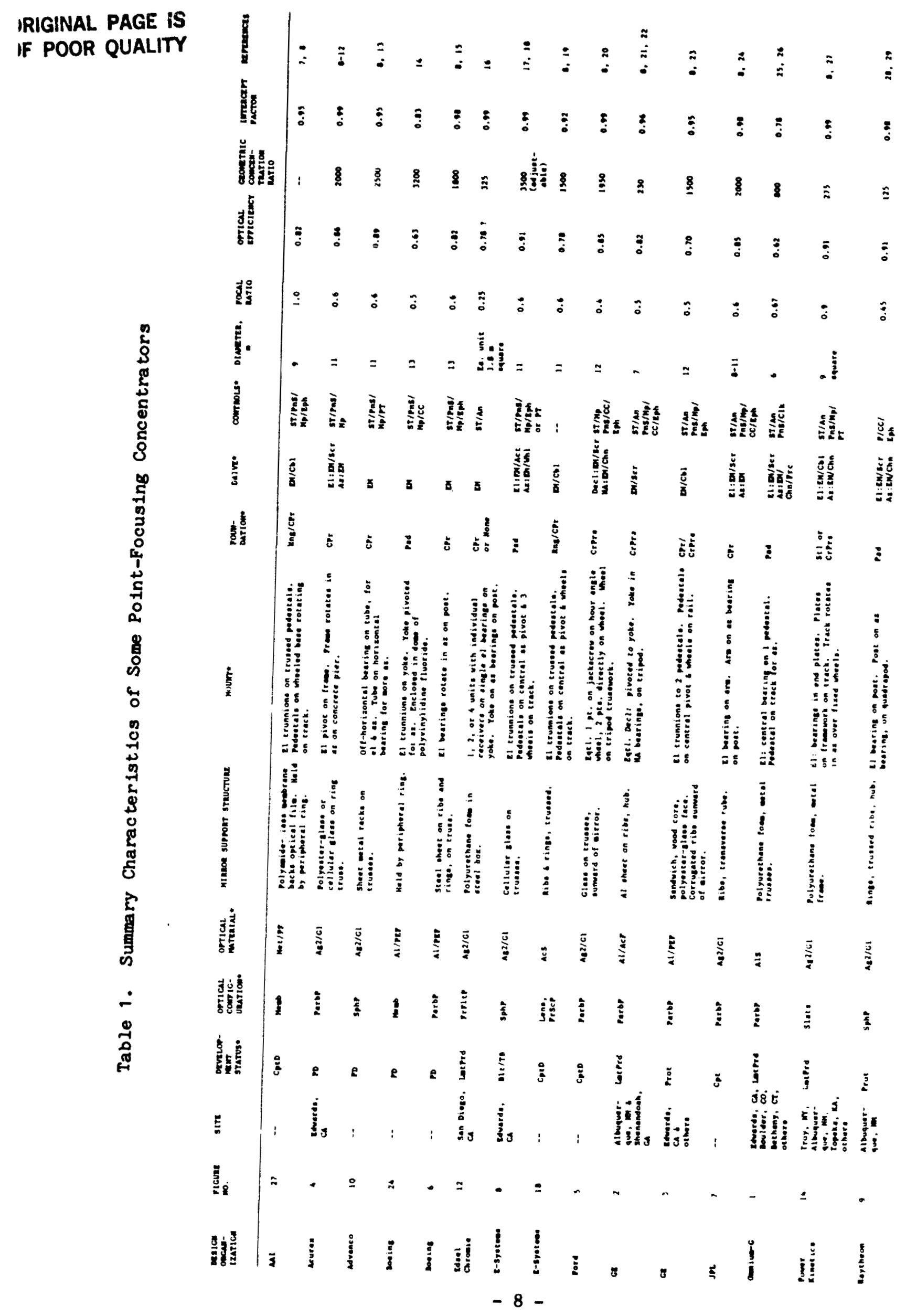




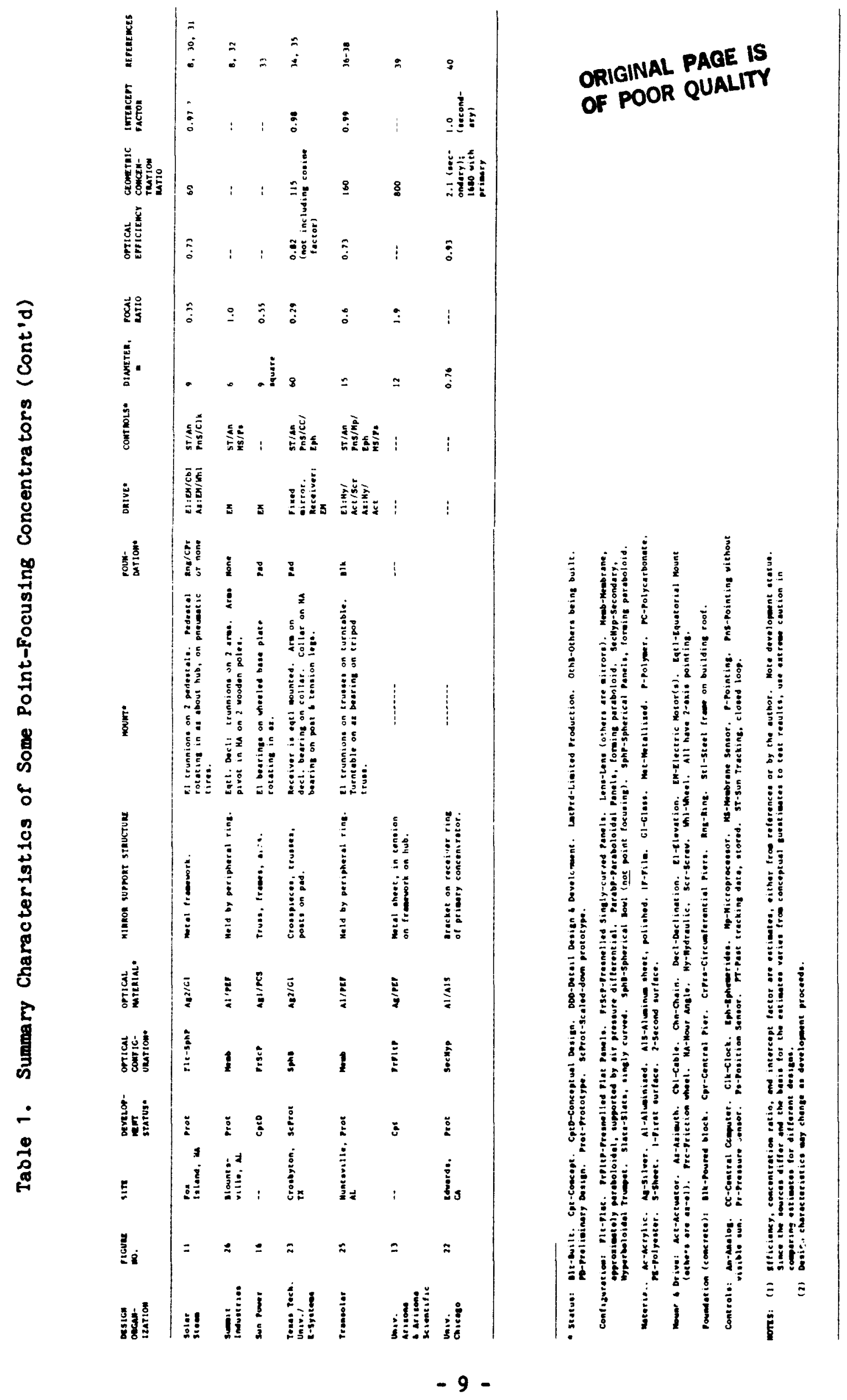


A concentrator need not consist of a single optical element (mirror or lens). Second and additional elements can be used, forming a compound concentrator. A secondary nirror may be employed to fold the optical path (F1g. 19). This permits shortening the pointable structure of the concentrator, which may save weight and cost. Folding may also permit weight-saving in the support of the receiver and power conversion subsystem and place these subsystems closer to the ground. A secondary (or tertiary) mirror or lens may be used to provide additional concentration or to increase the intercept factor above that provided by the primary alone (Figs. 20-22). A disadvantage of compound concentrators is the loss associated with reflection or transmission at the additional optical elements. Reference 44 discusses compound concentrators in more detail.

One other optical configuration that should be mentioned is the spherical mirror. Because the sun is always on its optical axis, the mirror need not be pointed; instead, the receiver can be moved to match the sun's motion. A spherical mirror, however, provides only a poor approximation of a point focus, and a spherical bowl is generally corsidered to provide a line focus along the sunline, rather than a point focus (Fig. 23).

\section{B. OPTICAL MATERIALS}

The classical optical material for solar concentrators is second-surface silver on glass (Figs. 4, 5, 7-12, 14, 23). This is reasonably durable but somewhat expensive (especially if the glass is curved), heavier than some alternatives, and fragile. Aluminum on glass seems to have no advantage over silver for solar concentrators. Its higher reflectance in the ultraviolet does not compensate for its lower reflectance in the infrared, which contains much more of the solar energy. Optical absorption by the glass is important in second-surface mirrors; therefore, very thin low-iron glass is favored.

First-surface glass mirrors do not incur optical losses in the glass, but an exposed front surface of silver or aluminum does not withstand weather well. Hence, a protective coating is needed over the reflective layer.

Metal sheet has the advantage of easy formability to doubly-curved shajes. Panels of polished aluminum sheet, generally with an anodized surface finish, have been used for dish concentrators (Fig. 1). Careful fabrication techniques are needed to attain a good optical contour, and the surface tends to lose its specularity and reflectance upon exposure to weather.

Polymeric films are attractive for mirrors because of their low cost (Figs. 2,$3 ; 6,13,16,24-27$ ). A vapor-deposited aluminum coating is the usual reflecting layer (F1gs. 2, 3, 6, 24-27). This may be first-surface, second-surface, or sandwiched between two polymer layers. A protective coating is used over first-surface aluminum, so the distinction between first-surface and sandwich is indefinite. Silver-coated polymeric film is not commerclally produced but is being investigated (F1gs. 13, 16). Polyester is the sost common polymer (Figs. 3,6, 13, 24-26); acrylis (Fig. 2) and polycarbonate (F1g. 16) are al so being trled. Polyester tends to yellow under exposure to ultraviolet light. If polyester is outside the aluminum layer or otherwise exposed, additives or special grades are needed to reduce yellowing. The long-time durability of all polymeric mirrors is open to. question and 1s the subject of active work. 
For lenses, polywers are lighter than glass and much easier to form to shape. Polymethyl methacrylate is a leading candidate (Fig. 18). There is evidence that, if properly formulated, this acrylic retains adequate transmittance during exposure to weather, but it is not known whether its surfaces degrade severely.

Many secondary concentrators operate at high temperatures. Aluminum is being tried for a secondary mirror (Fig. 22). Glass with low thermal expansion may be suitable for secondary lenses.

\section{MIRROR/LENS SUPPORT STRUCTURE}

The optical element itself can be supported in a number of ways. A mirror may be placed on a continuous structural backing of metal (Figs. 2, 6, 13), cellular glass (Figs. 4, 8, 10), polymeric material (often reinforced; Figs. 1, 3, 4, 12, 14), or wood (Fig. 3). The backing may be monocoque, sandwich, stiffened by integral or separate ribs, or supported by trusswork. Wires in tension may be used as part of the supporting framework. If a structural framework is used, the optical element may be rigid enough to support itself between the structural members (Fig. 5), or it may be flexible, held in shape by tension (Fig. 13). Lenses too can be monocoque or supported or stretched over a frame (Fig. 18). The monocoque structure, frames, or wires may in turn be supported by spars or rings which transmit the loads to the elevation bearings and drive.

Some designs support the reflector or lens by a peripheral structural ring; the optical element itself may be rigid or may be flexible, held in tension by stretching the element across the ring or by a pressure differential across the element. This pressure differential can be maintained by pumping air out of the space between the reflector membrane and a closure (Figs. 24-27).

\section{RECEIVER SUPPORT}

A structure is also needed to support the receiver and the equipment located with it, such as a power conversion subsystem. Various designs use tetrapods, tripods, bipods, and monopods. Considerations for design include rigidity to hold the receiver accurately in position, blocking and shadowing of the light, and distortions of the reflector or lens by gravity and wind loads of the receiver and power conversion equipment. The latter consideration favors carrying the receiver and power conversion loads directly to the elevation bearings and drive (Figs. 9, 12, 14, 23), rather than through the mirror/lens support structure.

\section{E. MOUNT AND FOUNDATION}

Dish solar concentrators most commonly use azimuth-elevation (naz-eln) mounting. Equatorial mounting is sometimes employed (Figs. 2, 5, 26) but crems to have little advantage if the control subsystem incorporates sun tracking or computer control, as is usually the case. In some faceted designs, pointing about one axis is provided by rotating the concentrator and pointing about the other axis by rotating individual facets (F1gs. 14, 16). 
Rotation in elevation can be provided by bearings near the center of the optical element (Figs. 1, 2, 4, 6, 7, 9, 10, 25), at ends of a diameter (Figs. $3,8,11,12,18,24,26,27$ ) or near an edge (Figs. 5, 16). Many designs have used trunnion bearings at the ends of a diameter, but the alternative approaches show promise of lower cost through reducing the size and weight of the mount. Edge-mounting keeps the concentrator lower to the ground, reducing wind loads and simplifying maintenance, with perhaps the disadvantage of increasing the exposure of optical surfaces to wind-blown sand and dust. Because it is difficult to balance moments with edge-mounting, the loads on the drive mechanism are higher, so the mechanism must be larger and may require more maintenance. In some mount designs, counterweights are used to help balance gravity moments.

With mounting at end points of a diameter or at an edge, the elevation bearings and optical element are usually supported on pedestals provided with wheels for azimuth rotation, running on a metal or concrete track, and with a center pivot to take side loads (Figs. $3,8,11,18$ ). Center mounts also may use wheels on a track (Fig. 1). The foundation design depends on the soil at the site. For most soil conditions, the track is supported by concrete piers or a concrete ring, and the pivot by a separate concrete pier. Alternatively, a concrete foundation pad may be used.

With center- or edge-mounting of the elevation portion of the concentrator, the elevation bearings may be supported by a tripod or a post (Figs. 2, 4-7, 9, 10). The azimuth bearing is near the top of the tripod or near the top or bottom of the post. A yoke mount too may be rotated on a single azimuth bearing at its center (Figs. 12, 14, 24, 25). A tripod may use piers or a pad for foundation; a post or ground-level bearing may use a single pier. Costs of the foundation and mount are very significant contributors to the cost of the concentrator; single post and pier construction generally appears to be cheapest, at least for concentrators of moderate and small size.

\section{F. DRIVE}

For driving a concentrator about two axes, a wide variety of gear, chain (Figs. 1, 5, 9, 14) and cable (Figs. 3, 11, 14, 18, 27) arrangements have been proposed, as well as linear actuators and jacks (Figs. 2, 4, 5, 7-9, 25). The source of mechanical motion is generally an electric motor, but occasionally a hydraulic device has been considered (Fig. 25). Using hydraulic drive with a pneumatic accumulator simplifies emergency stowing or drive off the sun if electrical power fails.

\section{G. CONTROLS}

Pointing may be pre-programmed and open-loop, using a solar ephemeris table or function generator, or may be tracking, through sun sensors and a closed control loop. Concentrators with tracking controls usually utilize an ephemeris to point tne concentrator approximately in the sun's direction to permit use of sensors with limited field of view and also to maintain approximate pointing when a cloud covers the sun. Sometimes past tracking data are stored and extrapolated in lieu of an ephemeris (Figs. 8, 10, 14), or a clock is used (Figs. 1, 11). Tracking control may be analog, digital, or hybrid; the ephemeris is provided digitally. If multipie dishes are used for 
a power system, pointing control may be implemented at the individual dish, centrally for the whole system, or partially centrally and partially at the dish. For digital control, a micro-processor at the dish or central station or a cini-computer at the central station may be used. Dish pointing control may be integrated with other portions of the system controls, such as control of power conversion and power conditioning subsystems. Sun sensors for tracking may sense either the direct incoming sunlight or the focused sunlight at the receiver. Sensing the focused sunlight provides automatic nulling of errors due to deflections of the receiver relative to the primary optical element, but requires sensors, such as thermocouples, that can withstand high temperatures, or, alternatively, beam attenuation. Sensors of incoming sunlight are usually some type of photoelectric device.

\section{H. ENCLOSURE}

Because wind loads are such an important factor in dish concentrator design, there is some advantage in enclosing the concentrator so that it is not exposed to wind. A transpar nt polymer film is an obvious choice for the enclosure. Glass could also be used, but would probably lead to a more expensive enclosure. Film or glass can be supported by a rigid framework; film may be supported instead by an air pressure difference provided by $a$ small pump (Fig. 24). The enclosure also protects the optical element from blowing sand, hail, rain, ice, ard snow. If the incoming air is filtered, accumulation of dust on the surface is reduced. The enclosure will also reduce incoming ultraviolet light, which contributes very little to the total energy collectable and may cause degradation of polymers used in concentrator optics.

On the other hand, there will be significant transmission and reflection losses at the enclosure, and there may be a problem in fincing a suitable polymeric film for its construction. The cost of the enclosure is not negligible, and precautions must be taken to assure that the concentrated beam does not burn a hole in the enclosure if the concentrator is pointed slightly off-sun. Also, the enclosure will be much larger than the primary optical element: If washing is necessary to keep optical surfaces clean, the cost of washing the large enclosure is likely to be more than the cost of washing a smaller unenclosed reflector or lens.

\section{STATE-OF-THE-ART}

Figures 1 through 14, 16, 18, and 24 through 27 illustrate types of dish concentrators recently or currently recelving attention in United States, mostly under U.S. Department of Energy sponsorship. Only a few have been built and tested; others are in various stages of design. Their status is indicated in Table 1, together with estimates of their principal technical characteristics. Current emphasis is on low lifetime cost in volume production with adequate performance at the receiver operating temperature. For electricaf power production, interest centers around receiver temperatures of 400 to $900^{\circ} \mathrm{C}\left(700\right.$ to $\left.1700^{\circ} \mathrm{F}\right)$, with some consideration of higher temperatures for the future. For industrial process heat, the temperature range is broader.

As the figures and the table show, a wide variety of concepts are being considered. New, Innovative concepts continue to be introduced. 
ORIGINAL PAGE

BLACK AND WHITE PHOTOGRAPH

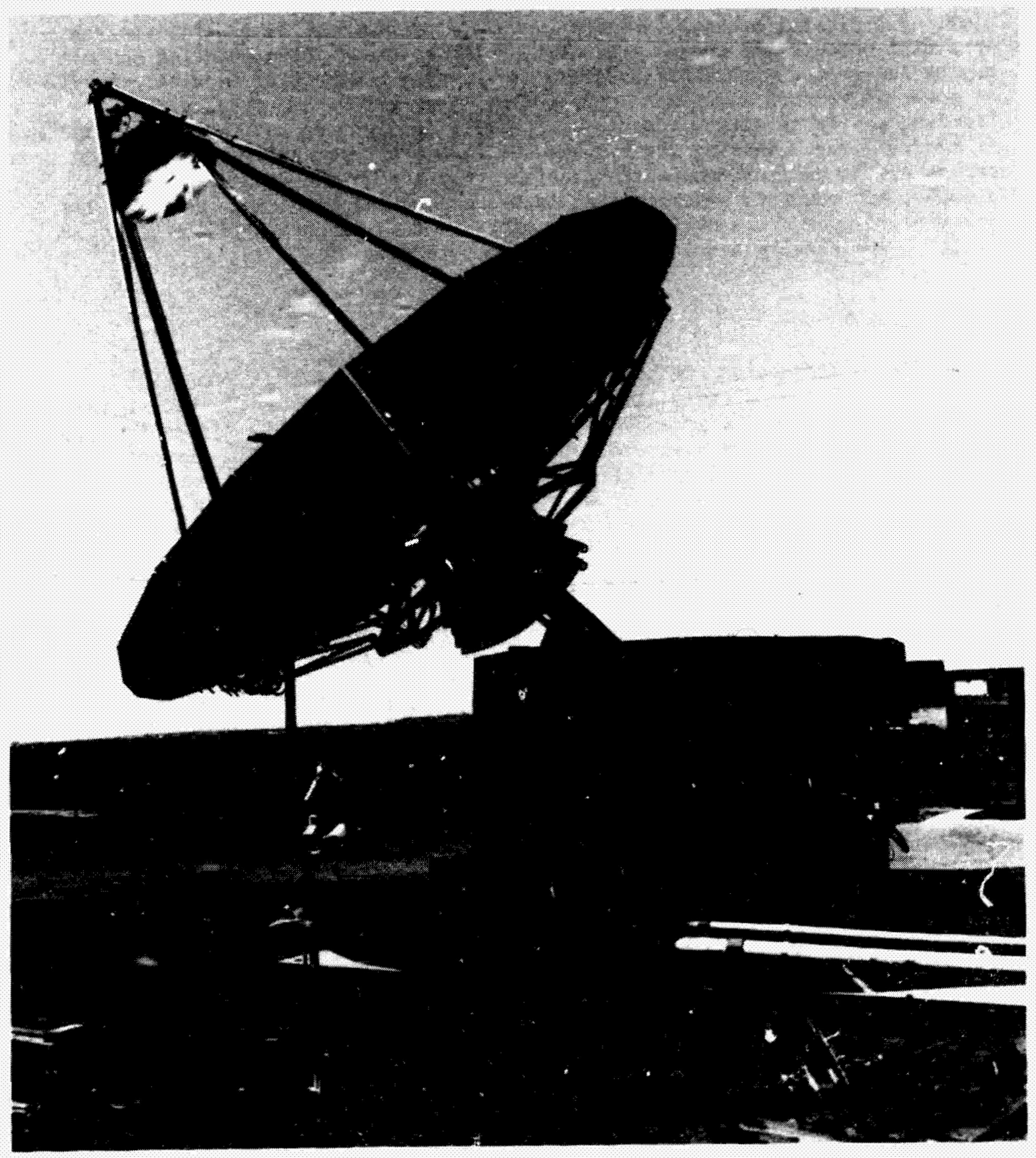

Figure 1. Omnium-G Concentrator 
CRIGINAL PAGE

BLACK AND WHITE PHOTUGRAFH

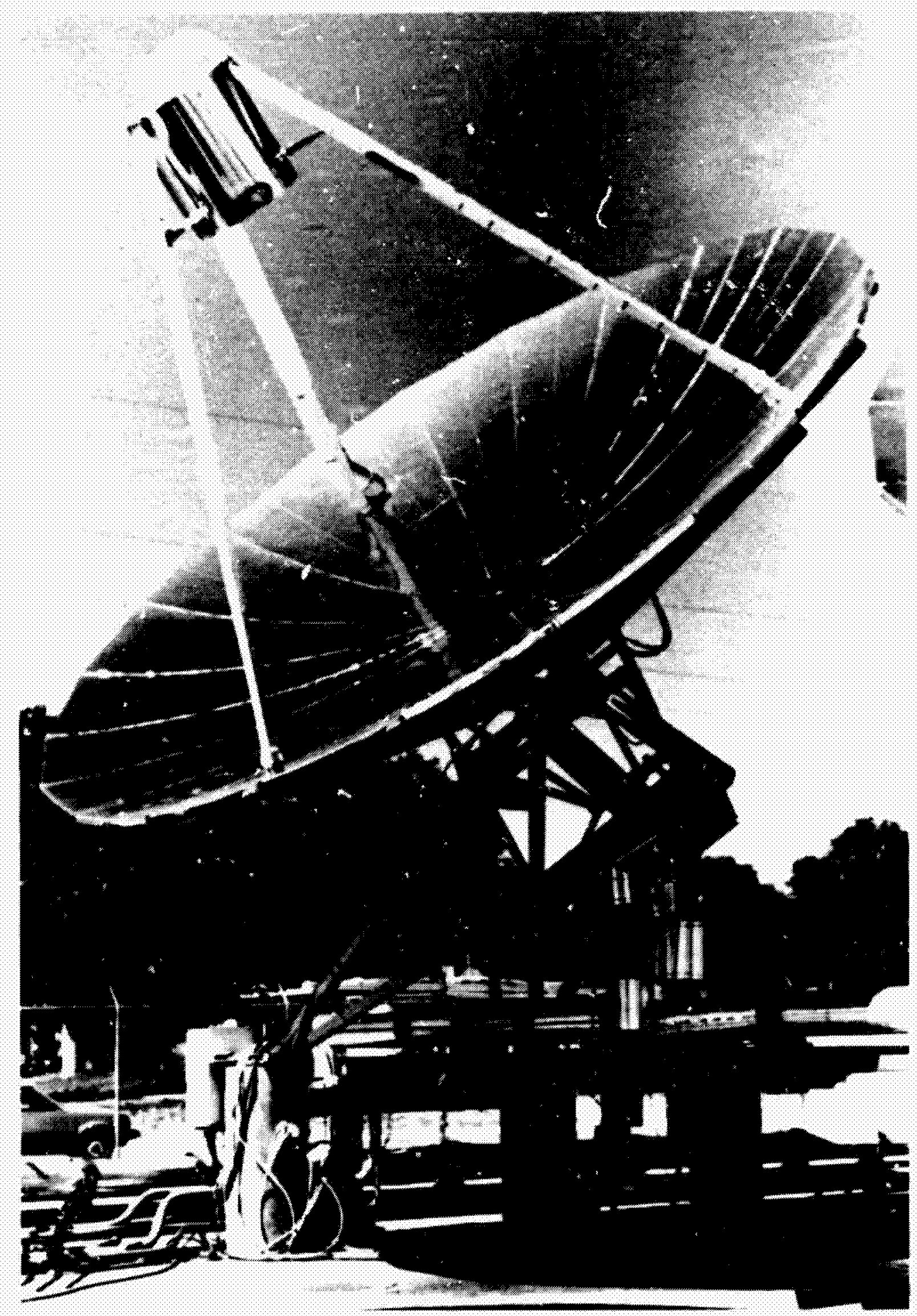

Figure 2. Shenandoah Concentrator (Listed in Table 1 under designer, Ceneral Electric) 
ORIGINAL PAGE

BLACK AND WHITE PHOTOGRAPH

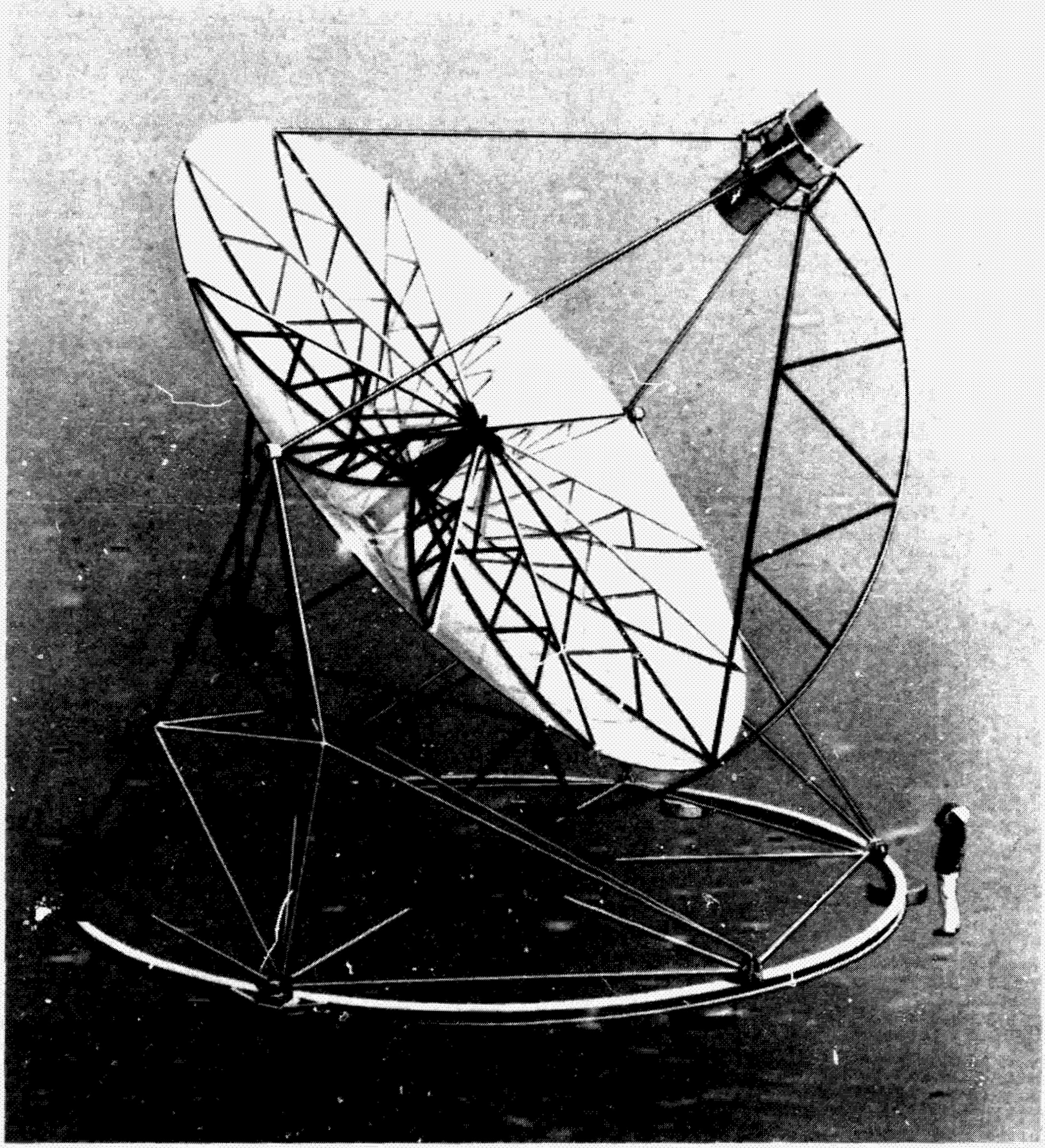

Figure 3. General Electric Concentrator 
ORIGINAL PAGE

BLACK AND WHITE PHOTOGRAPH

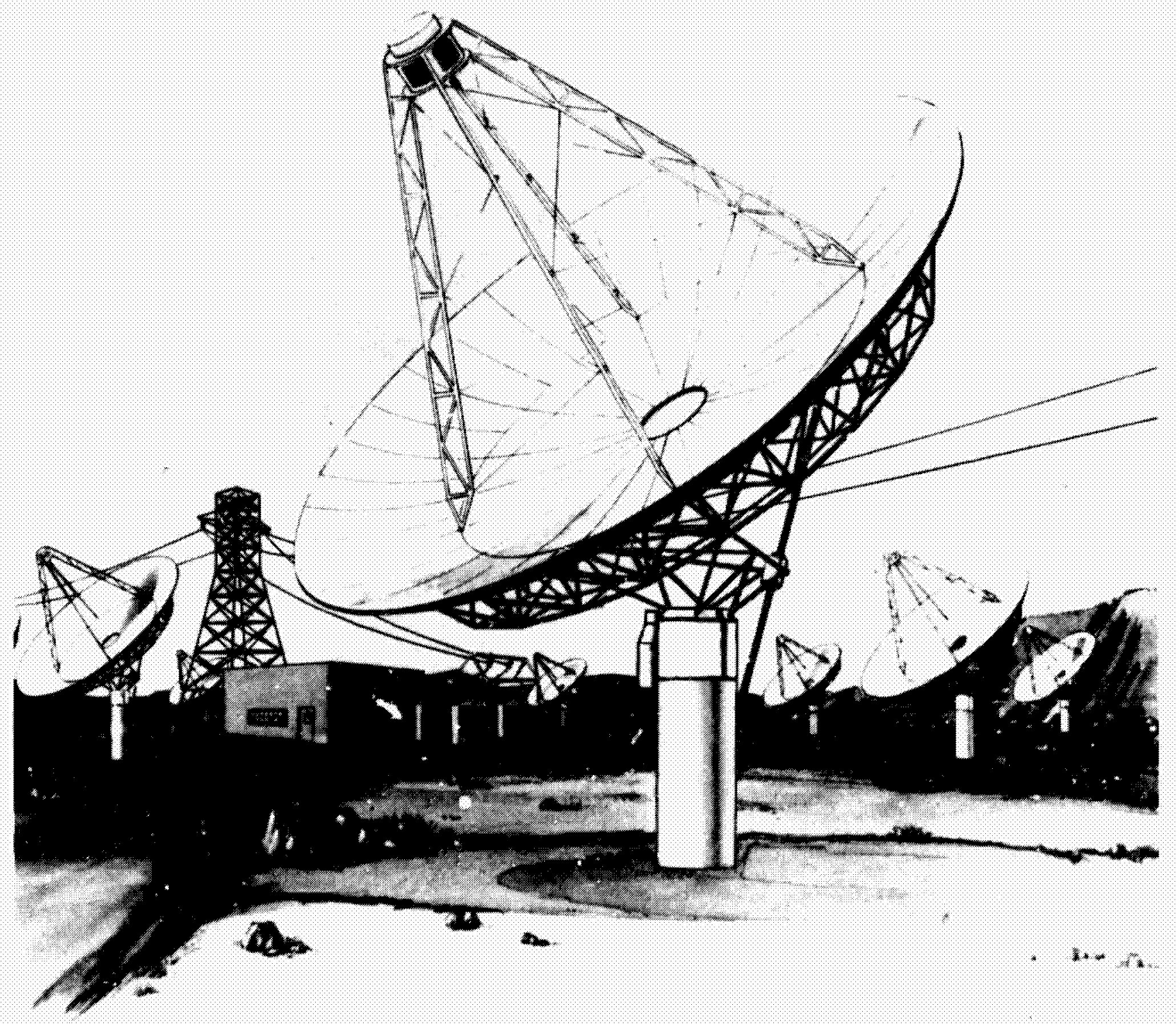

Figure 4. Acurex Concentrator 
ORIGINAL PAGE

BLACK AND WHITE PHOTOGRAPH

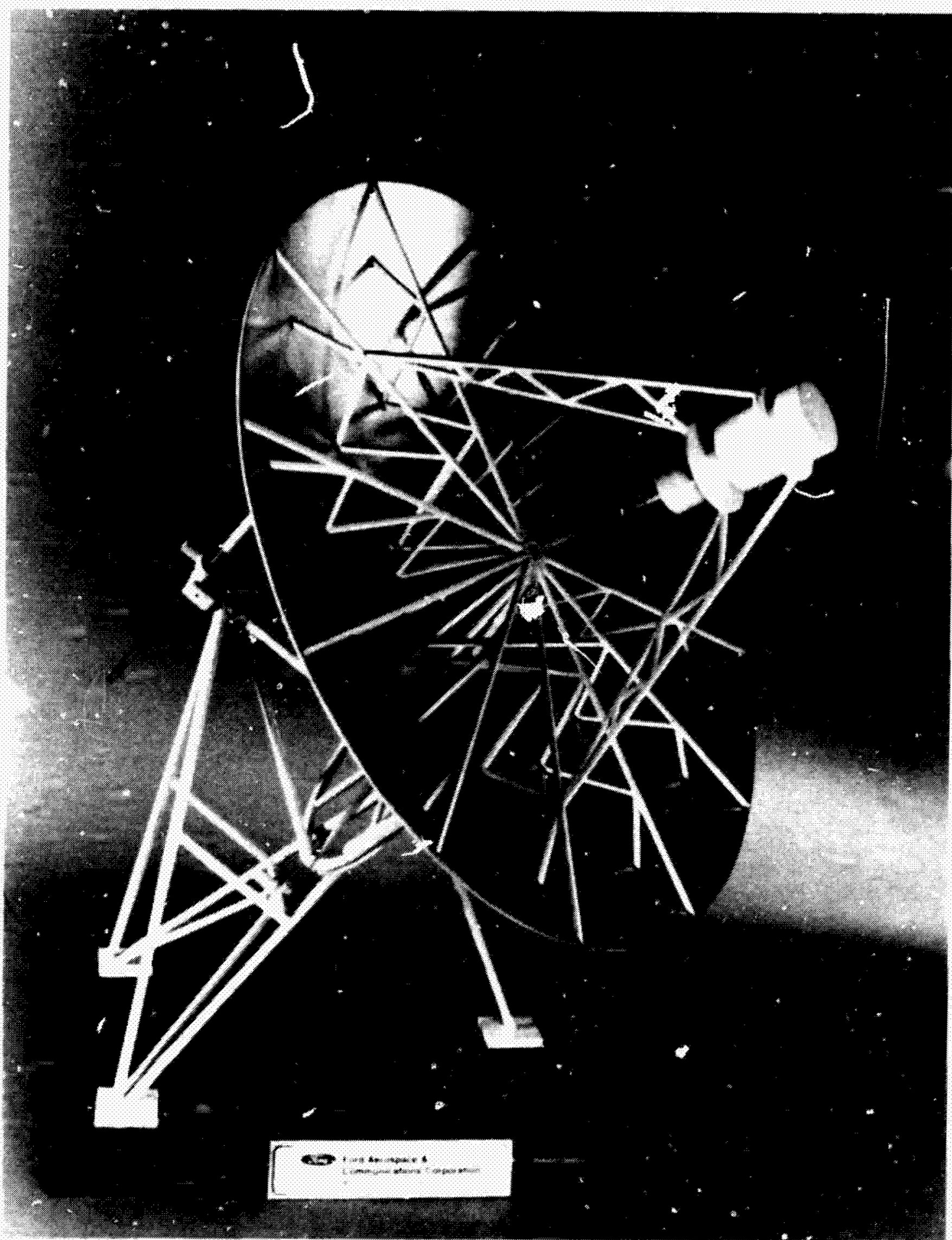

Figure 5. Ford Concentrator 


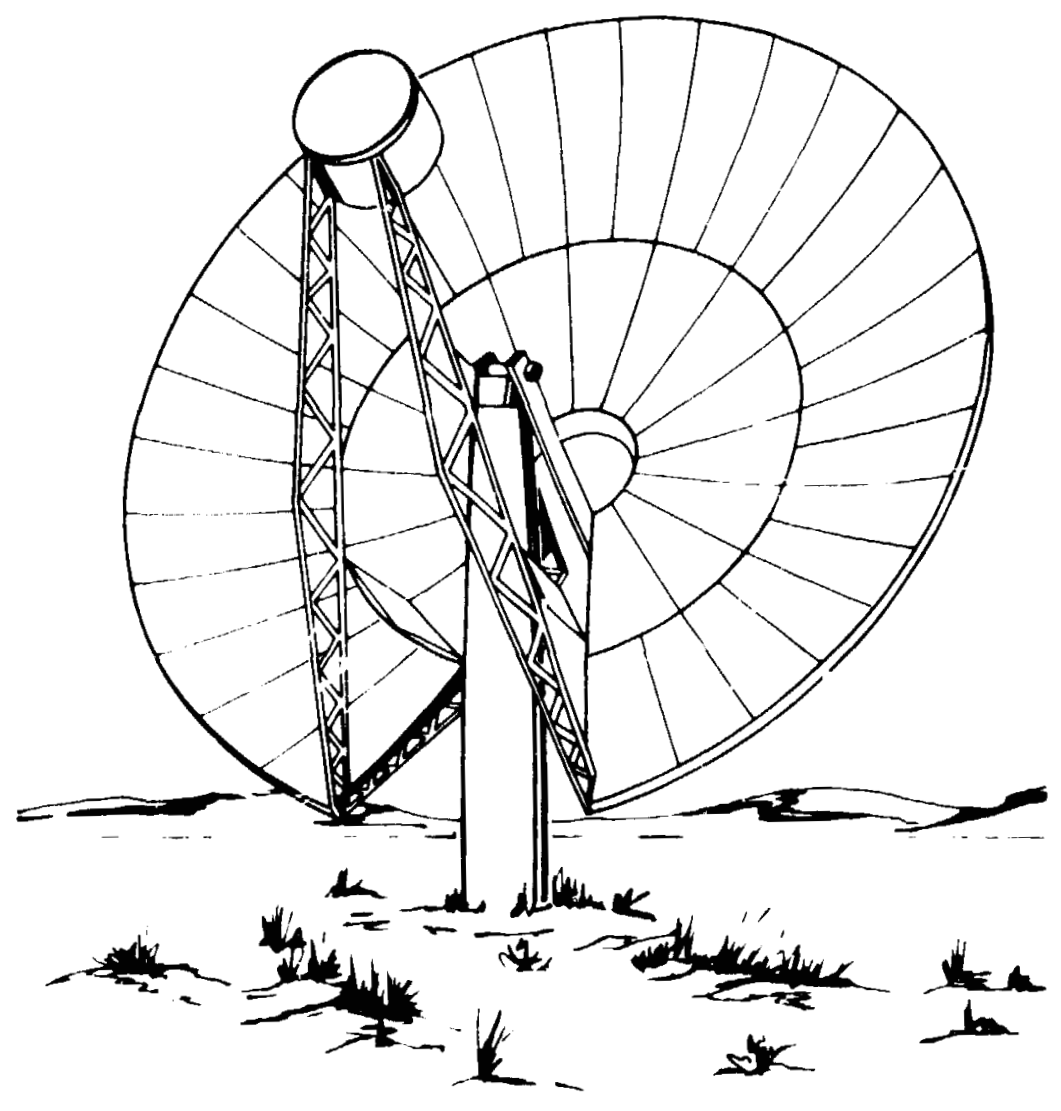

Figure 6. Boeing Coricentrator 
ORIGINAL PAGE IS

OF POOR QUALTY

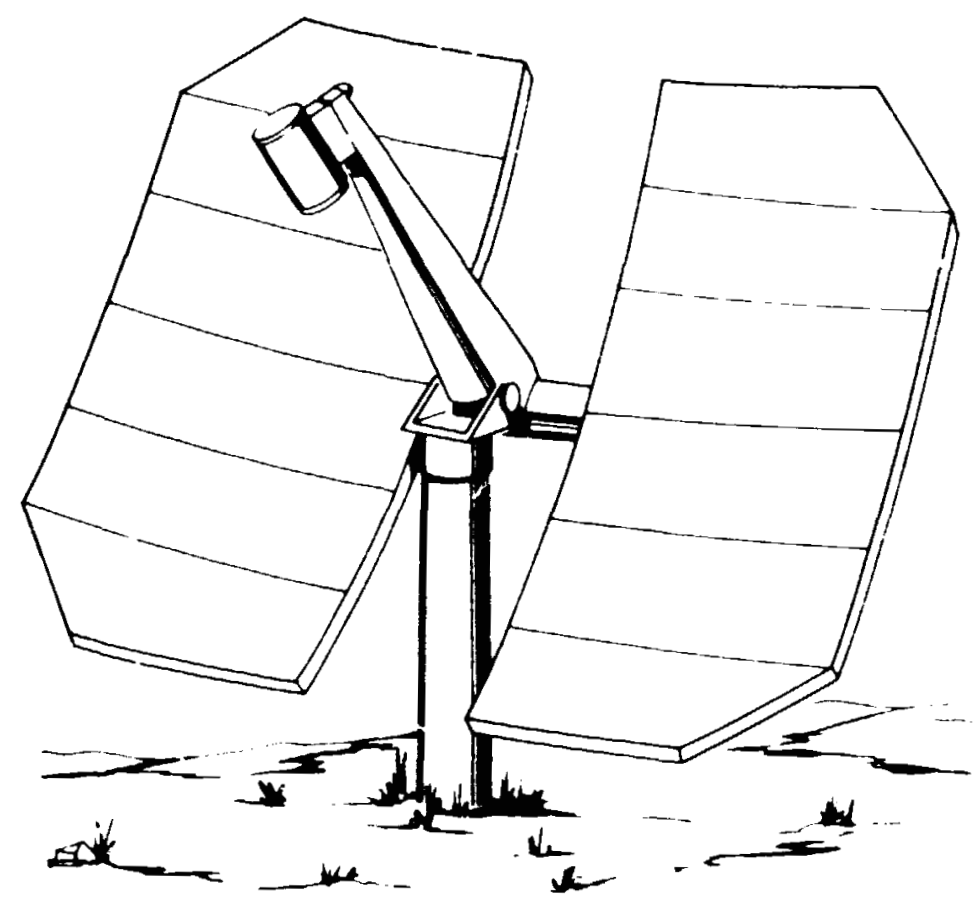

Figure 7. JPL Heliostat Adaptation 


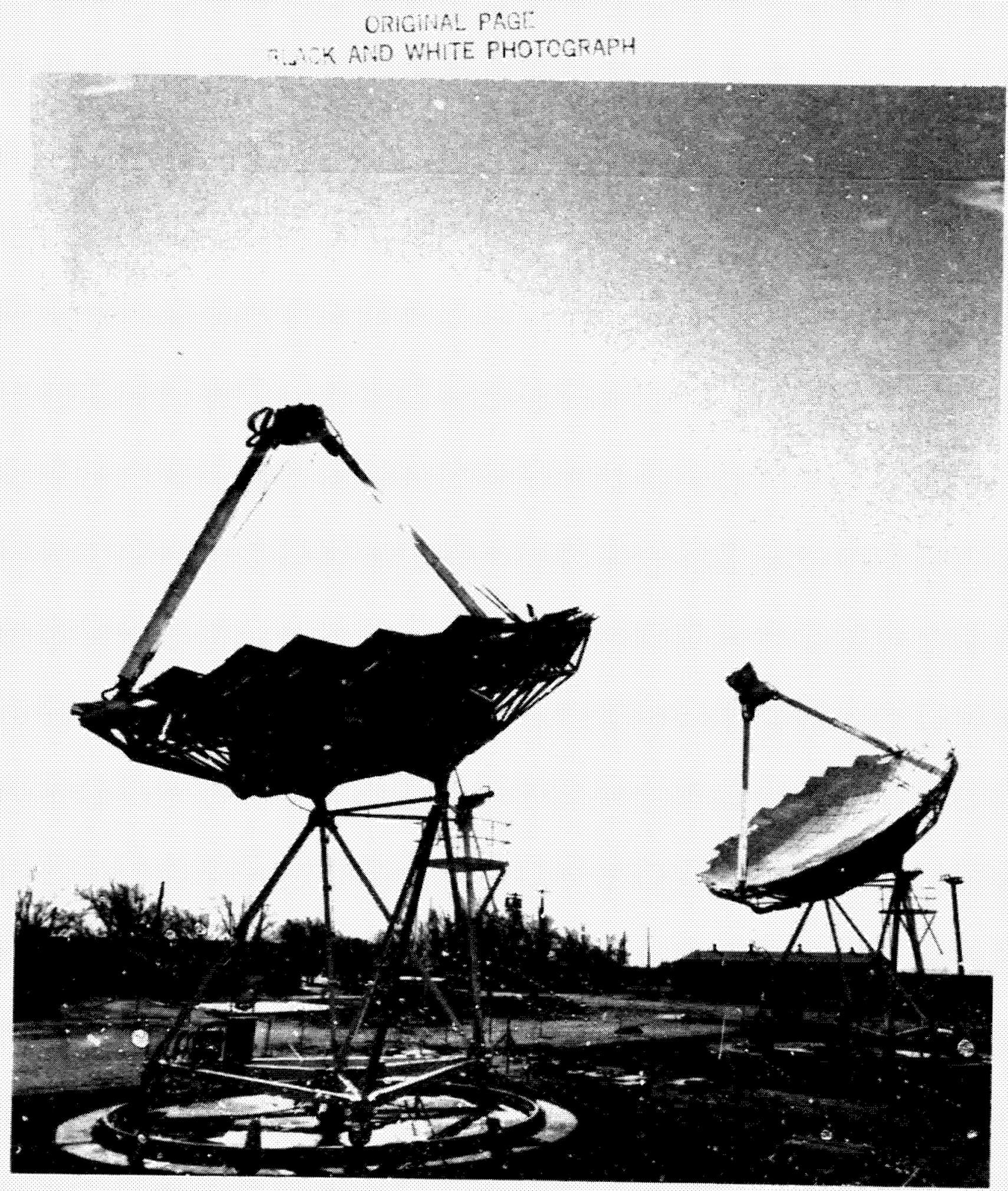

Figure 8. E-Systems/JPL Test Bed Concentrator 
ORIGINAL PAGE

BLACK AND WHITE PHOTOGRAPH

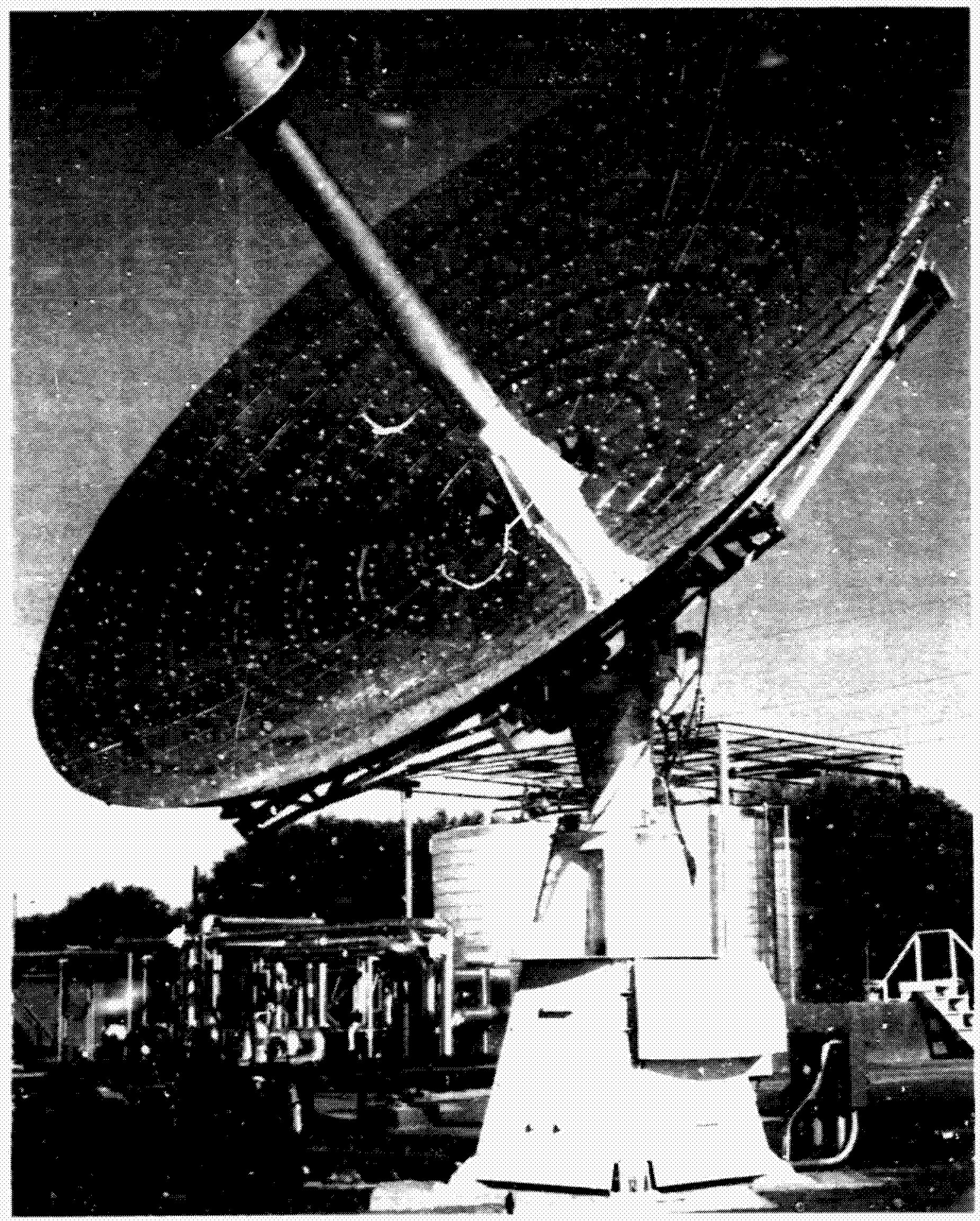

Figure 9. Raytheon Concentrator 
ORIGINAL PAGE IS

OF POOR QUALITY

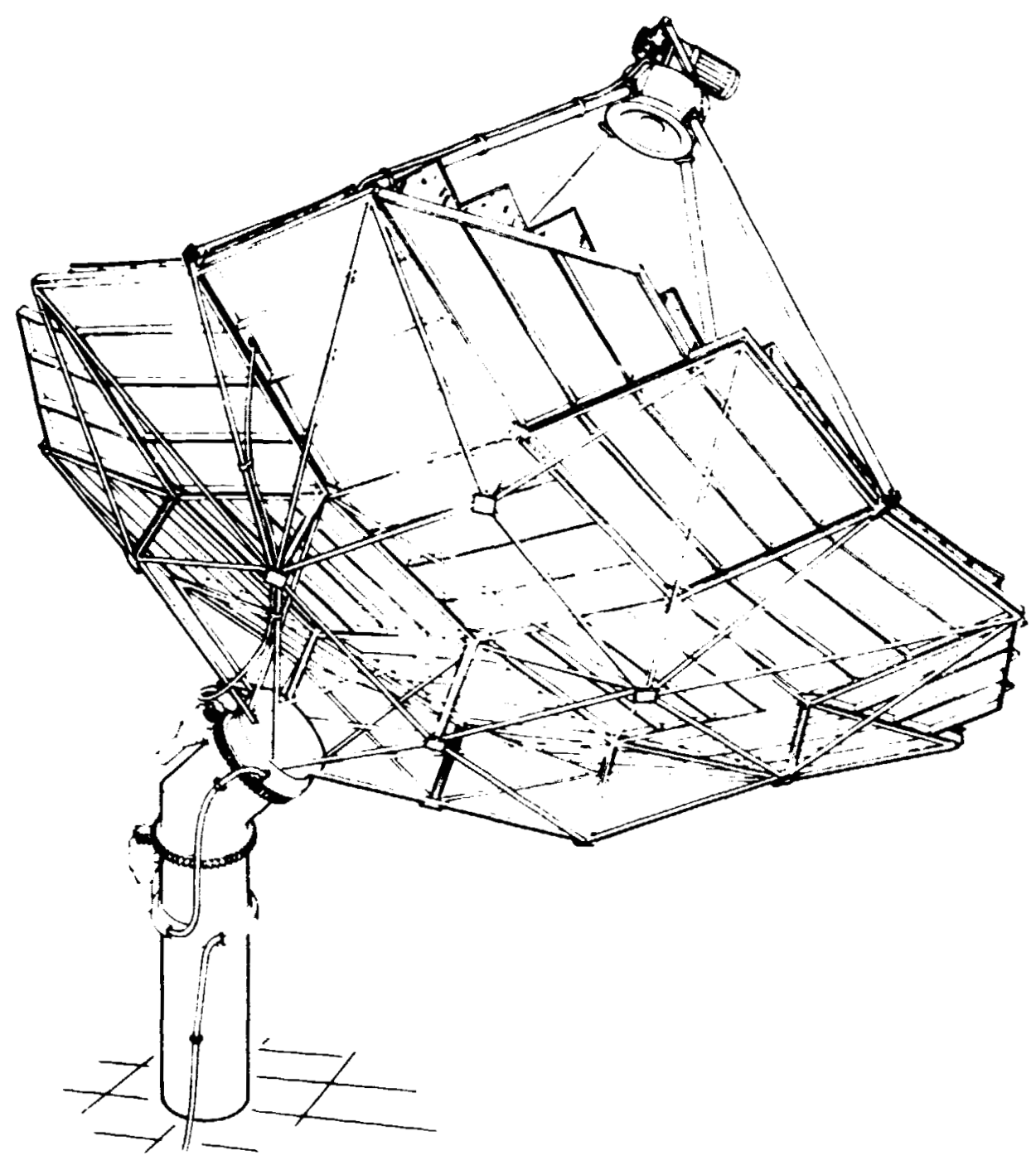

Figure 10. Advance Concentrator

- $23-$ 


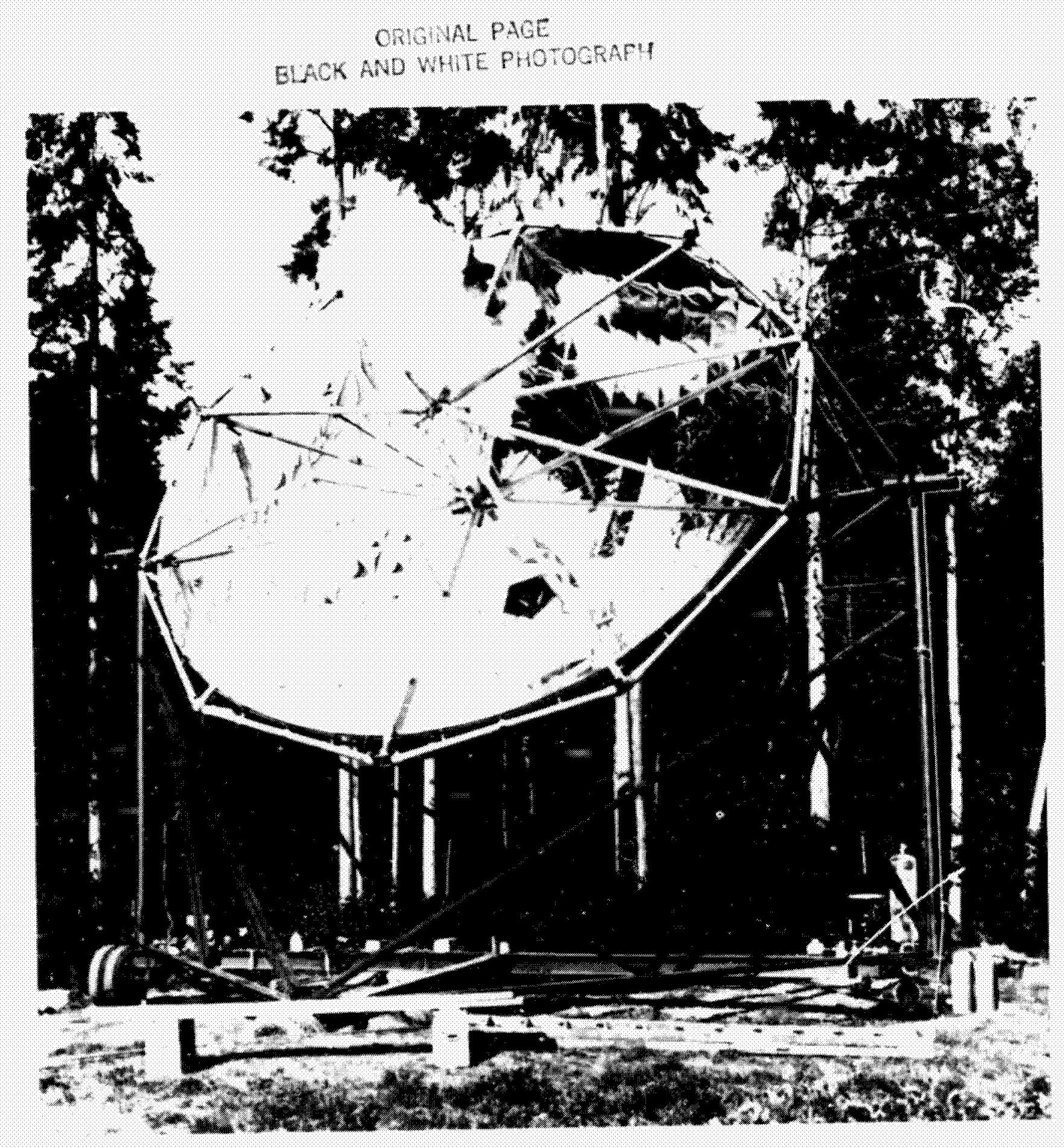

Plare 11. Solar Stean Concentrator 
ORIGINAL FAGE IS

OF POOR QUALITY

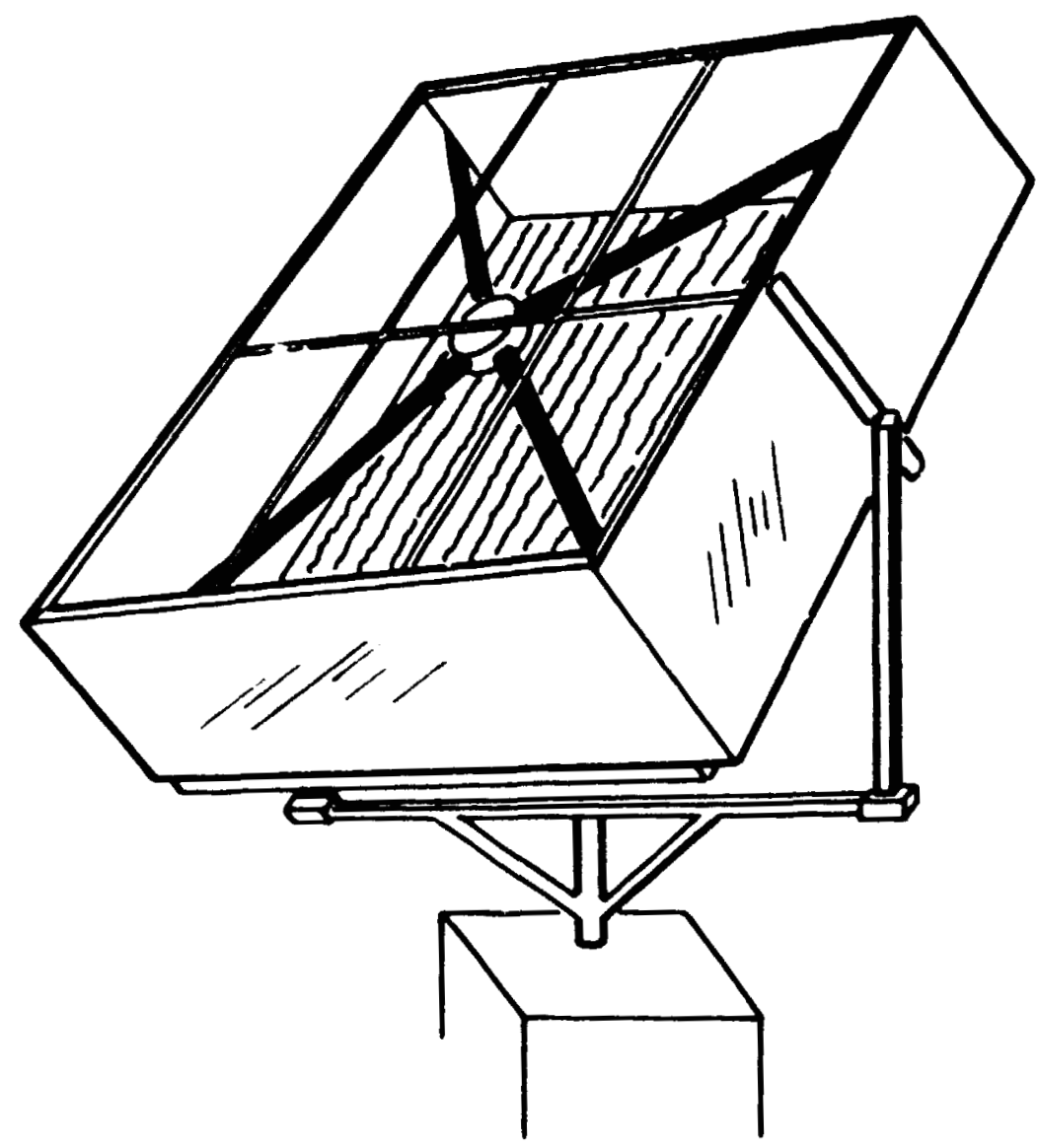

Figure 12. Sol-Trac Concentrator (Listed in Table 1 under designer, Edsel Chronde) 


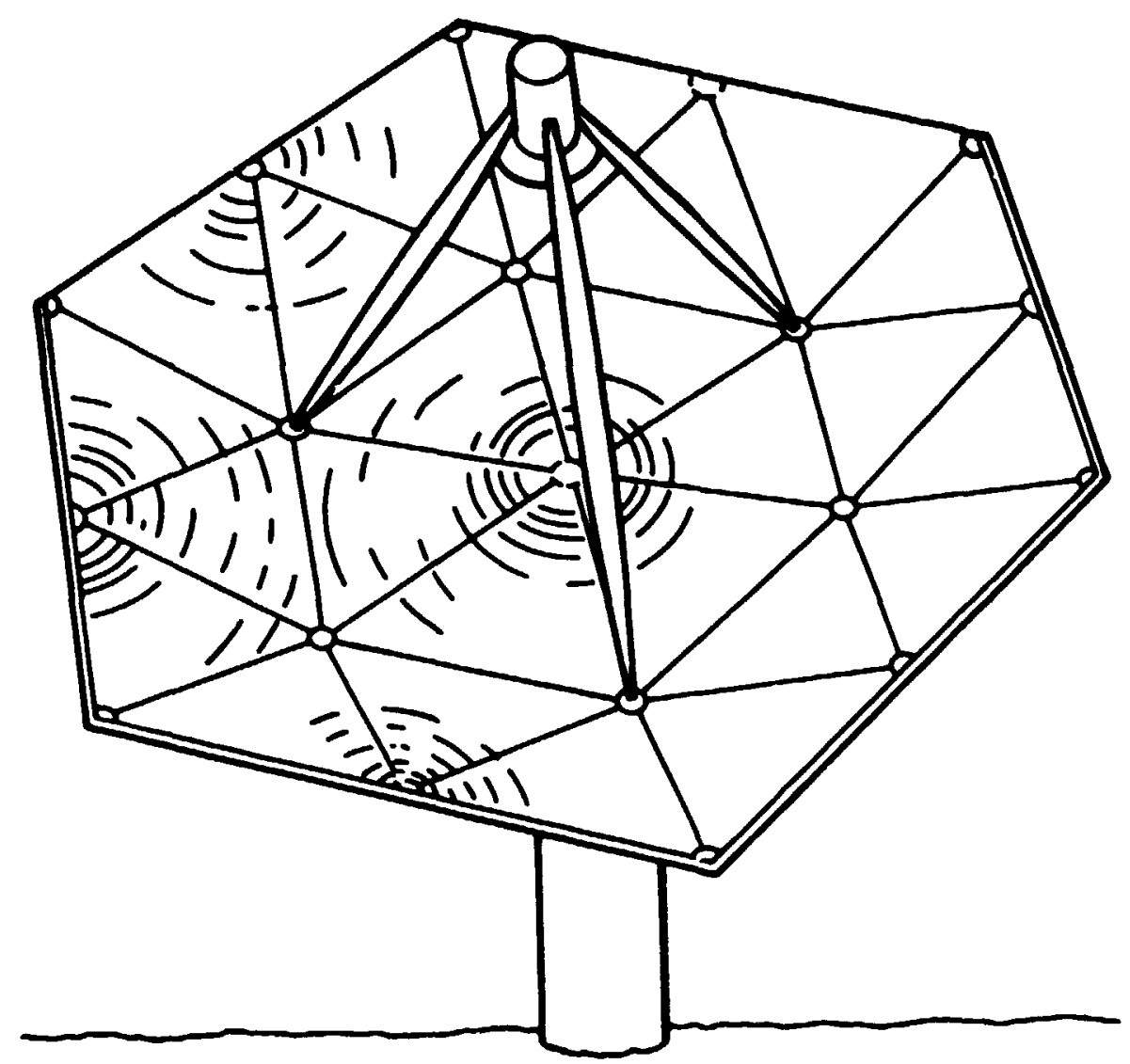

Figure 13. University of Arizona Concentrator 


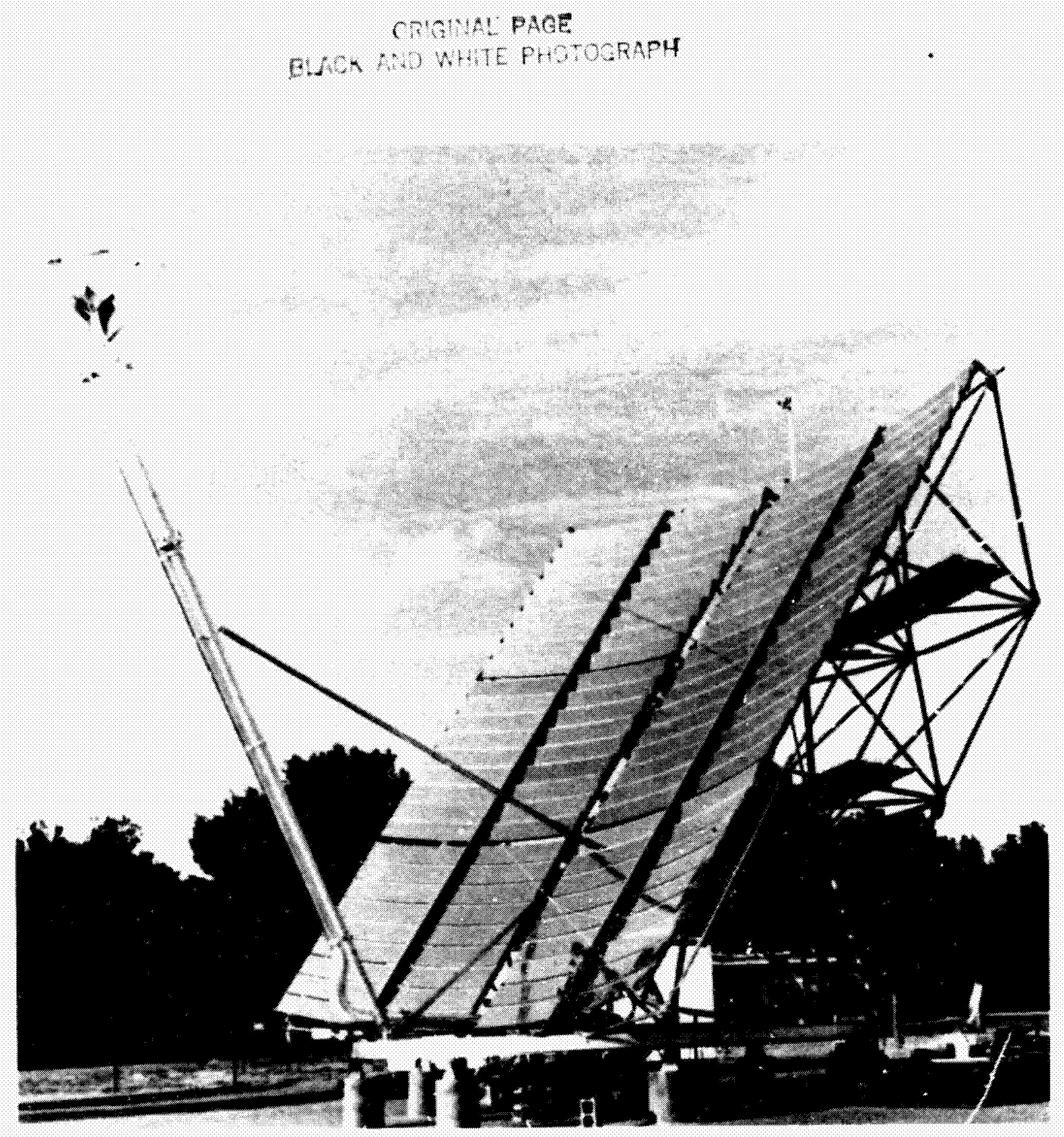

Figure 14. Power Rinetics Concentrator 


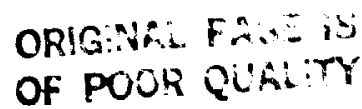

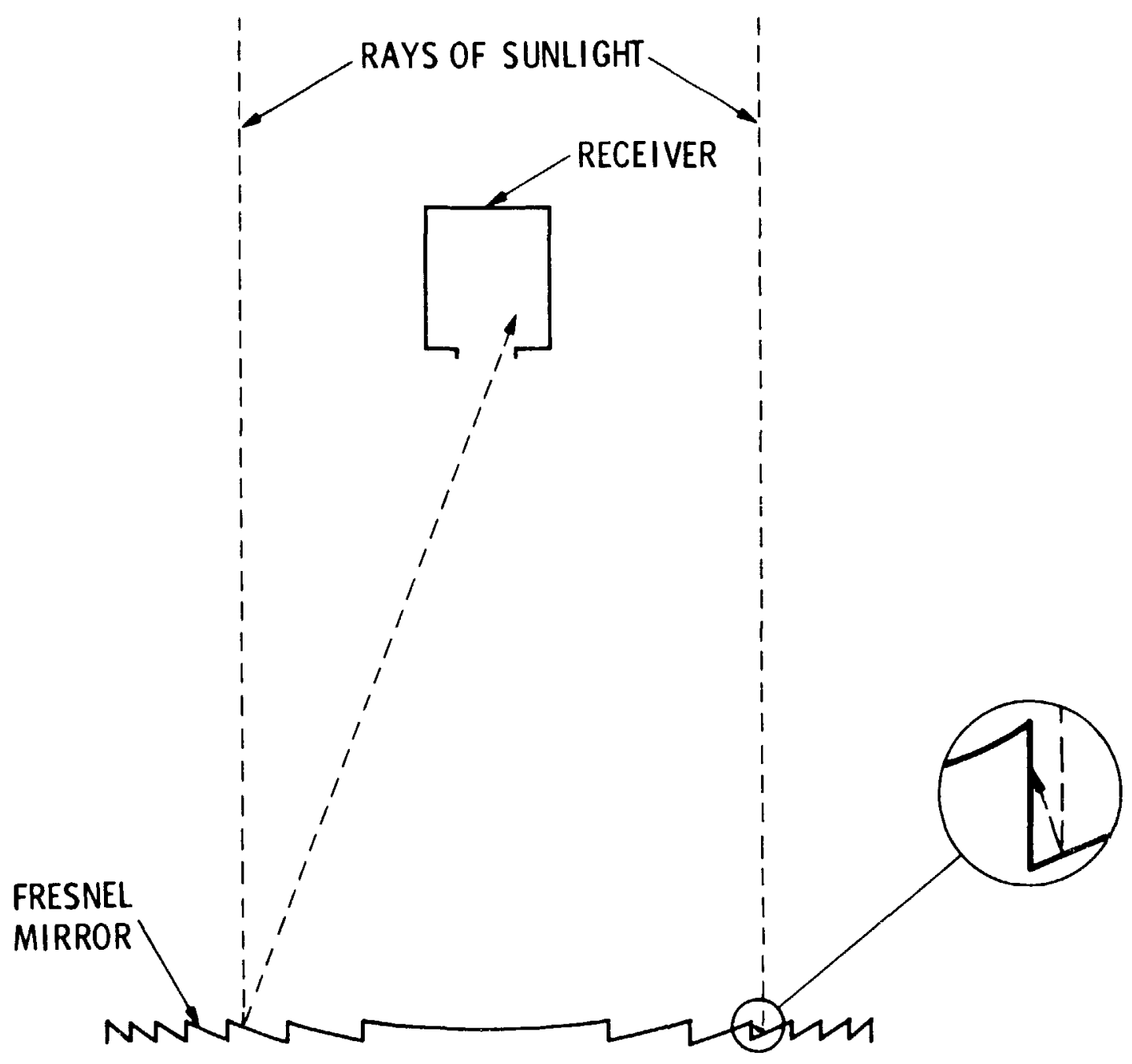

Figure 15. Sketch of Fresnel Mirror Concentrator (Note blocking of light at facet edges.) 
ORIGINAL FAEZ :S

OF POOT QuAlity

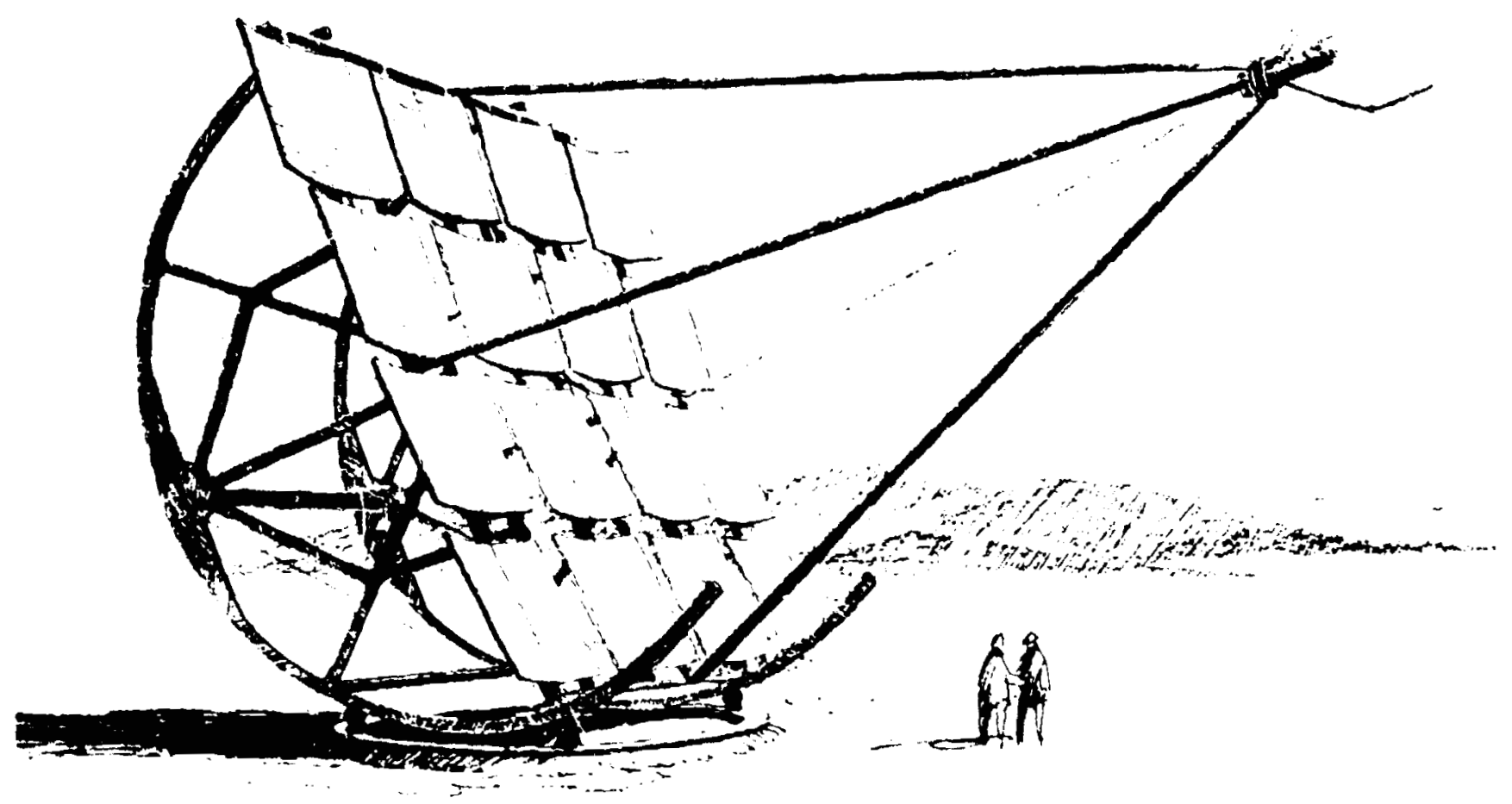

Figure 16. Sun Power Fresnel Concentrator 


\section{ORIGINAL PAGS is}

OF POOR QUALITY

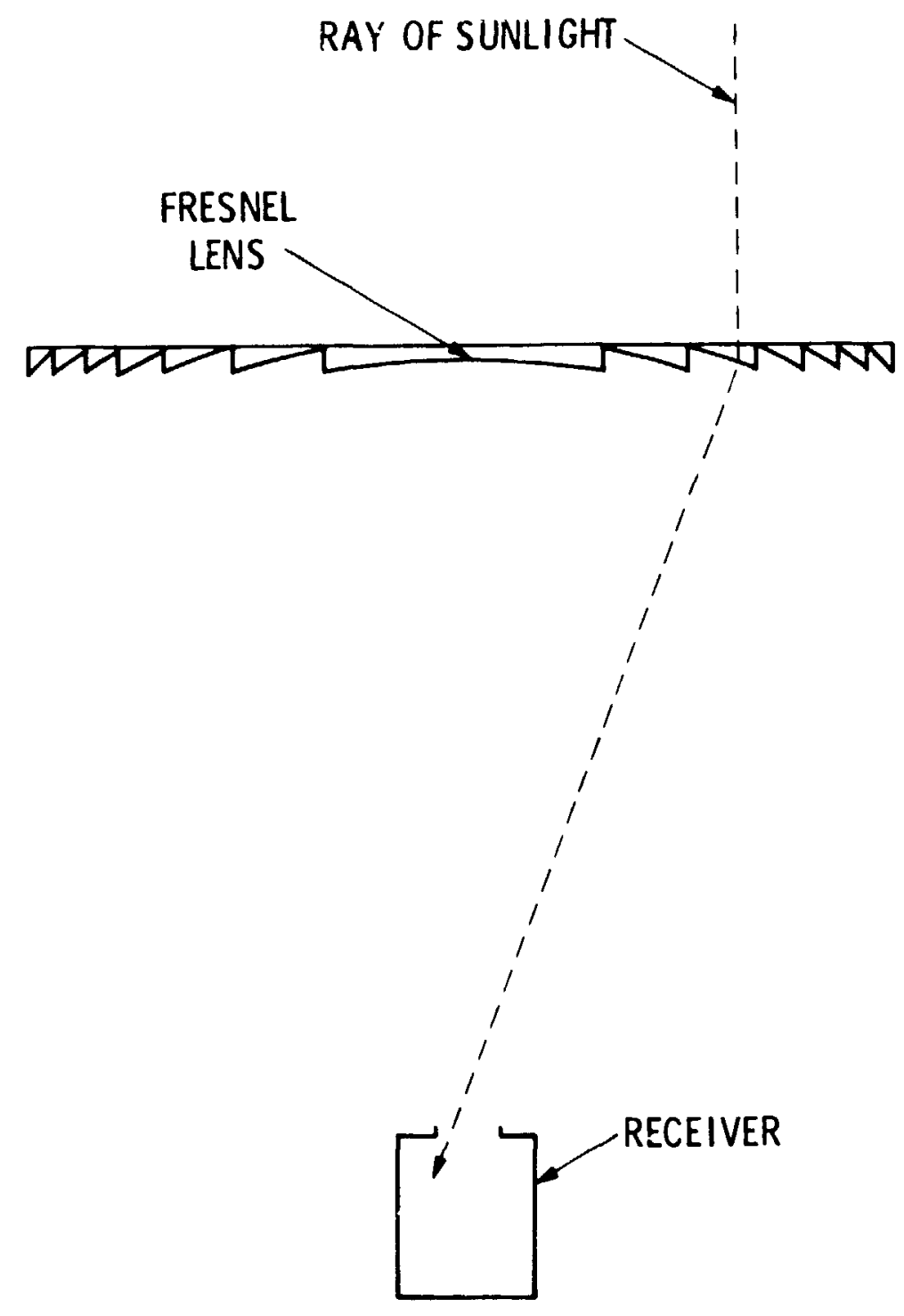

F1gure 17. Sketch of Fresnel Lens Concentrator 
ORIGINAL FAEE IS

OF POOR QUALITY

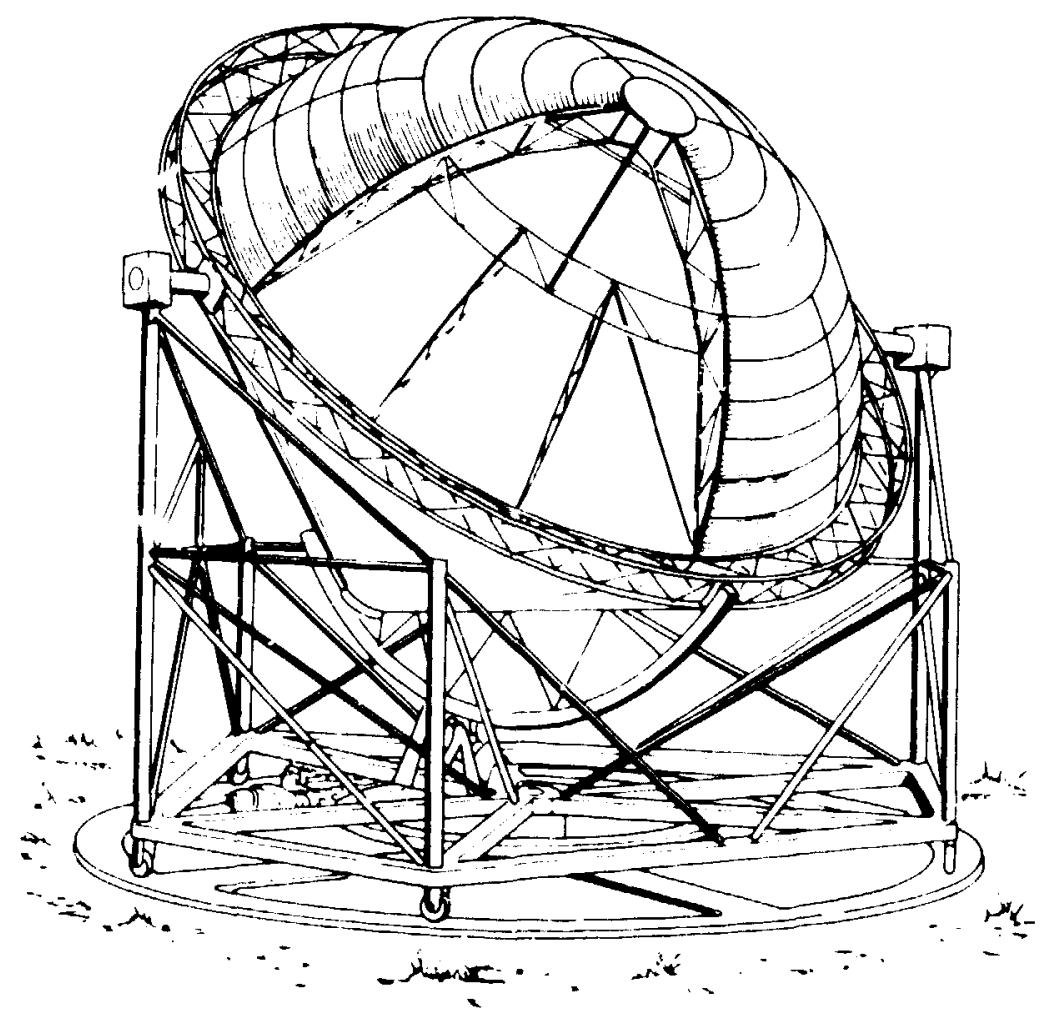

Figure 18. E-Systems Fresnel Concentrator 


\section{ORIOINAL PAGE IS \\ OF POOR QUALITY}

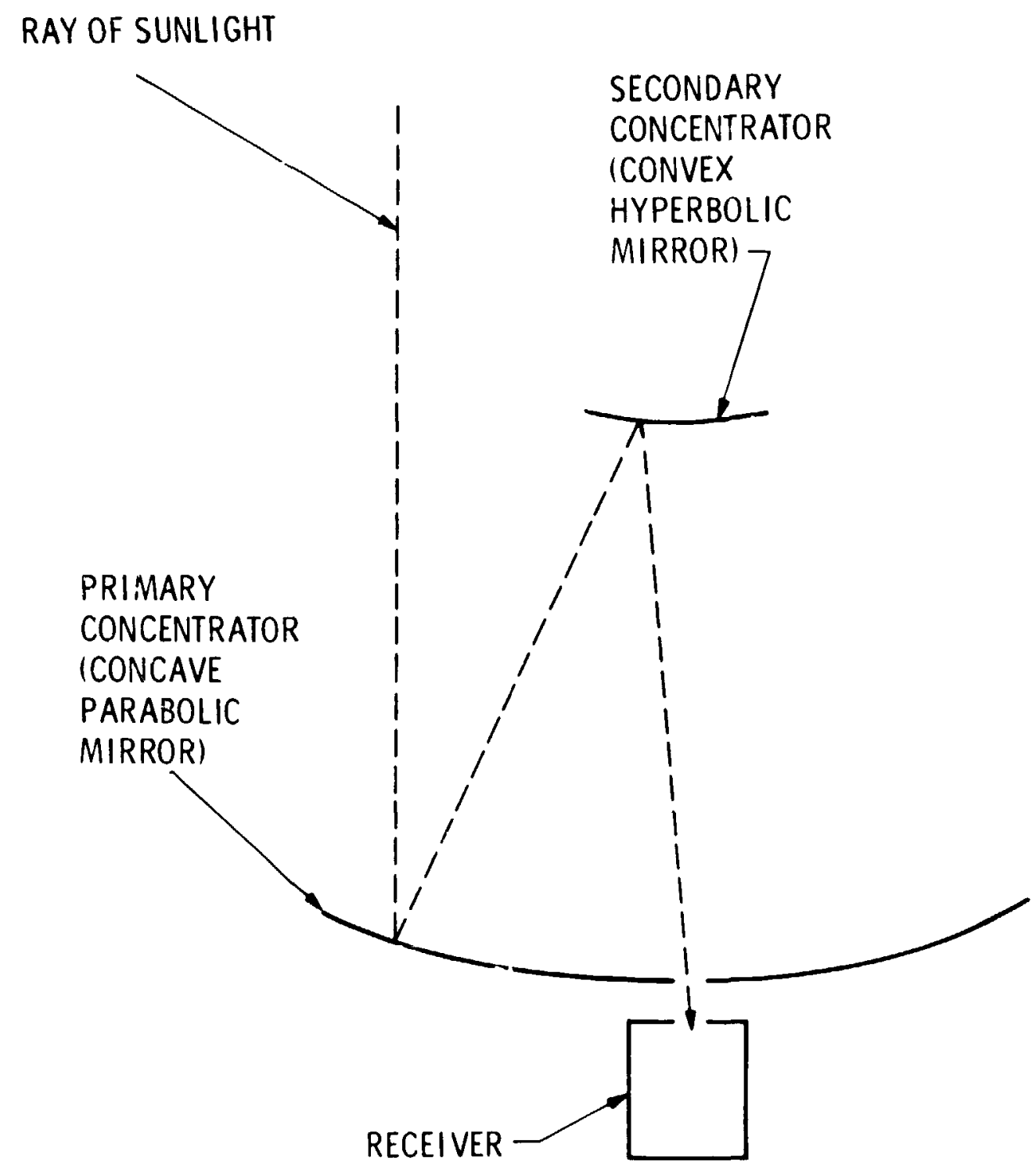

Figure 19. Compound Concentrator Using Secondary Concentrator to Fold Optical Path (Cassegrainian Configuration) 
CRIGINAL PAGE IS

OF POOR QUALITY

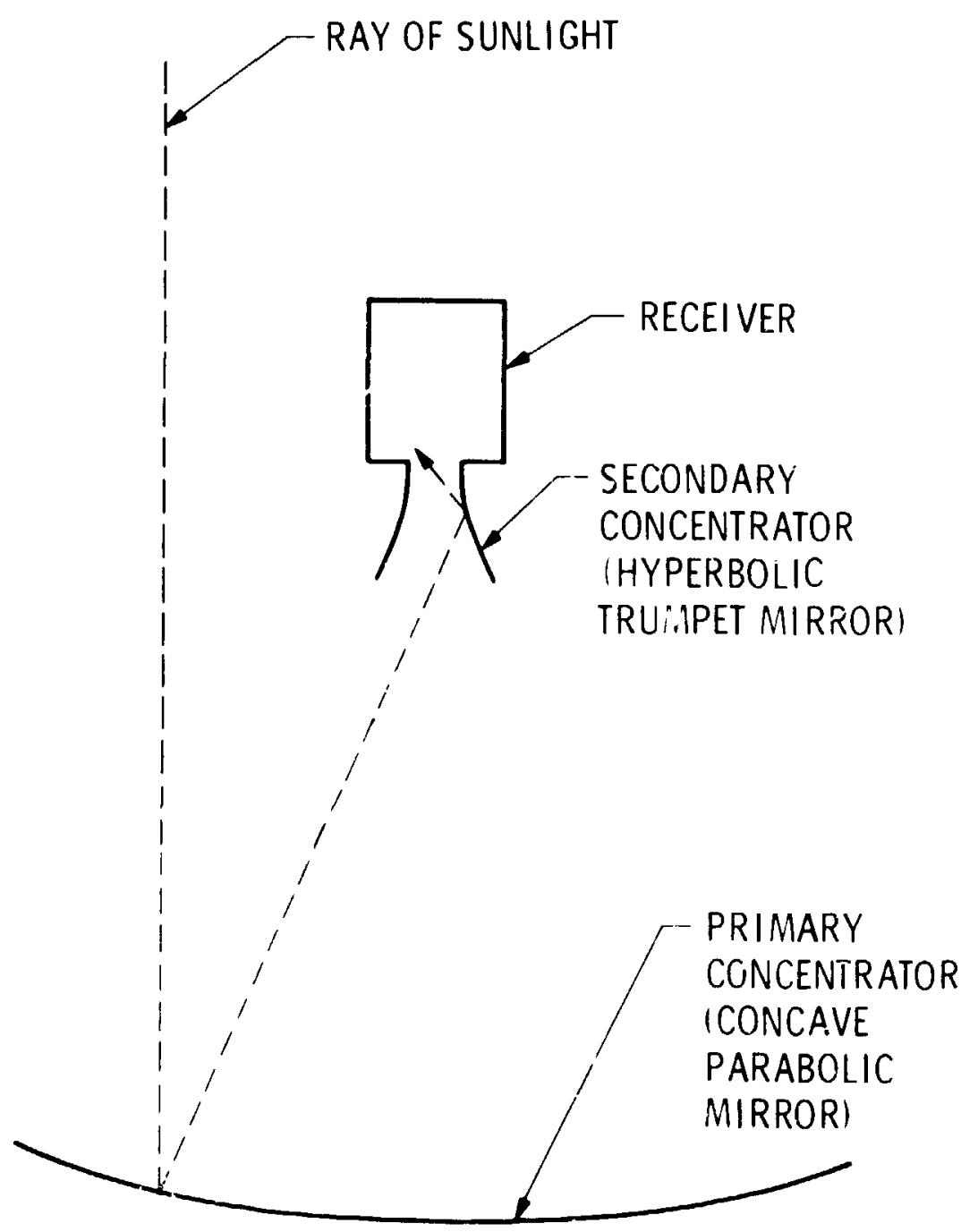

Figure 20. Compound Concentrator Using Secondary Concentrator to Increase Concentration 


\section{ORIGINAL PAGE IS OF POOR QUALTY}

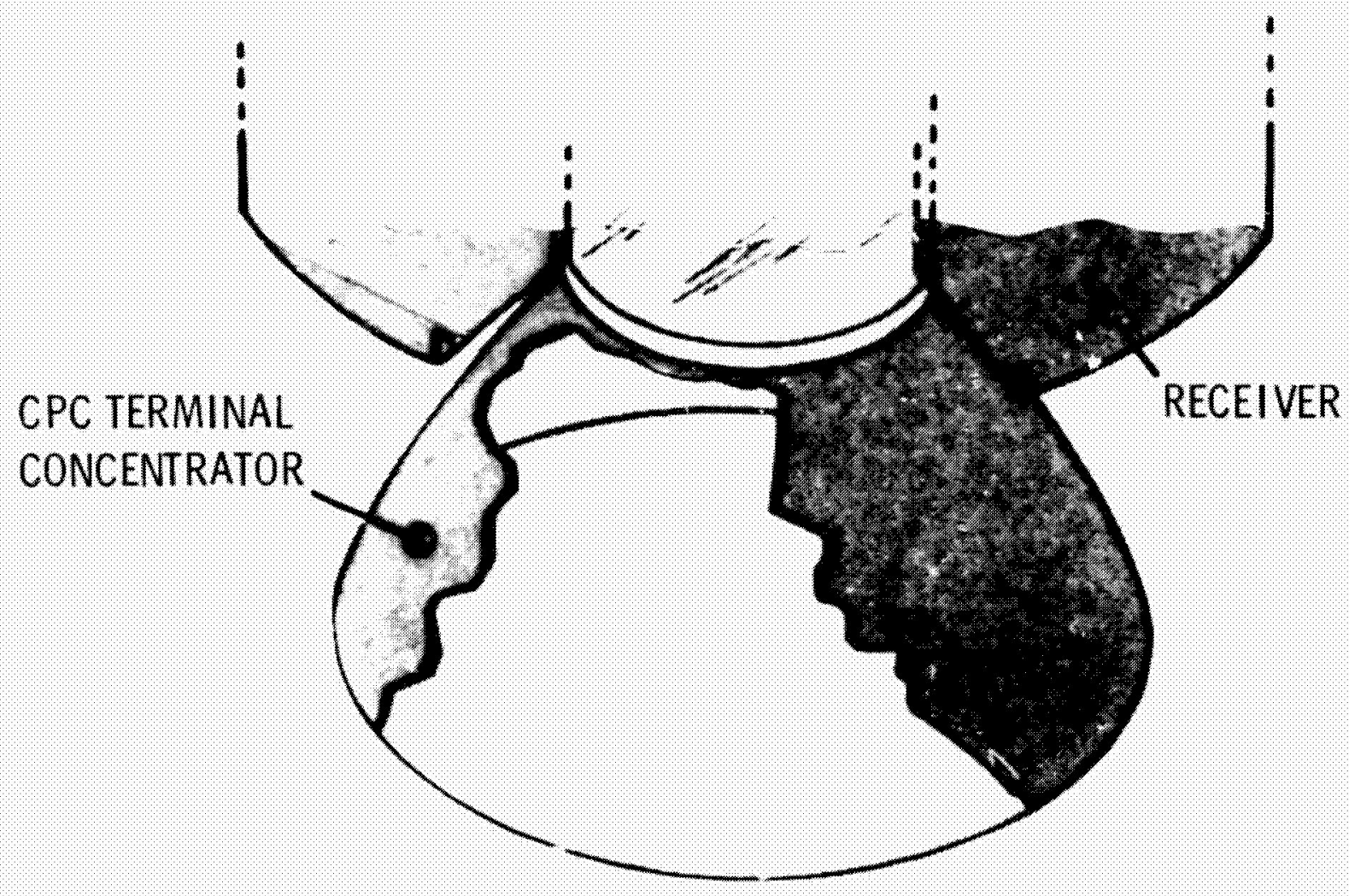

Figure 21. Sanders Recelver with Secondary Concentrator (Primary concentrator not shown; Ref. 43) 


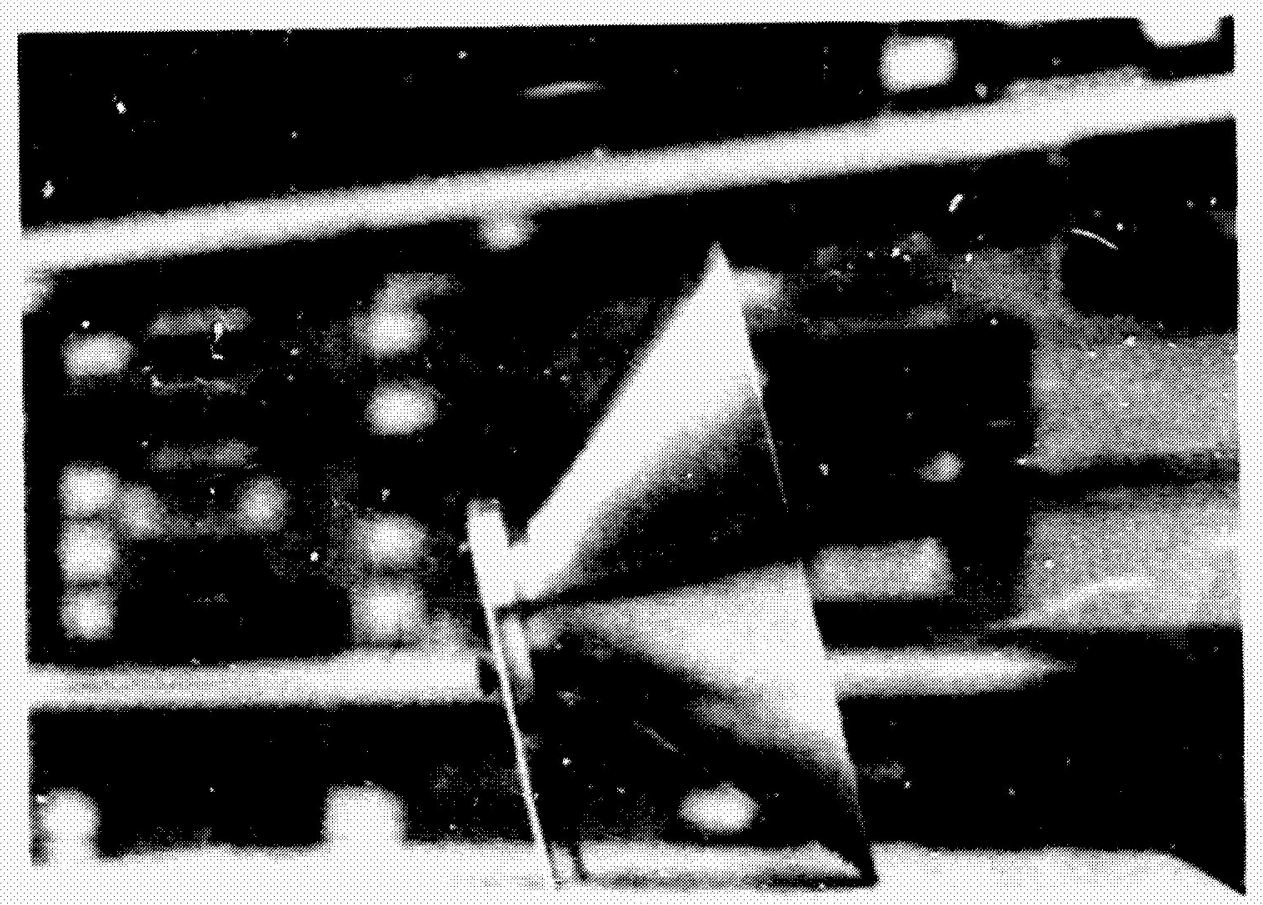

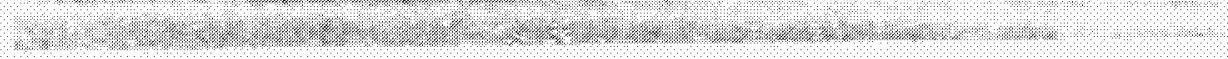

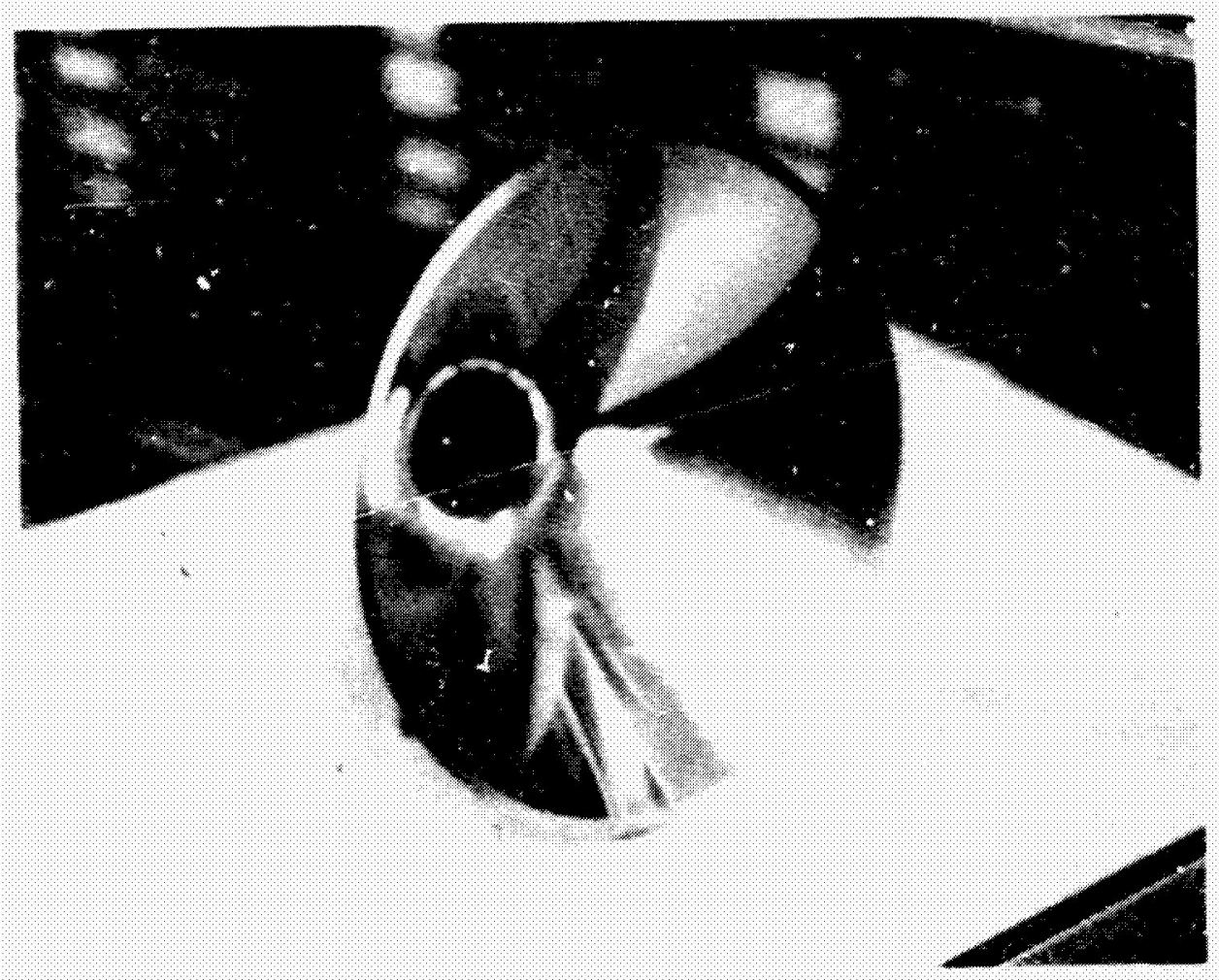

Figure 22. University of Chicago Secondary Concentrator (Used with prinary concentrator of Fig. 1) (two views) 
ORIGINAL PAGE

BLACK AND WHITL PHOTOGRAPH

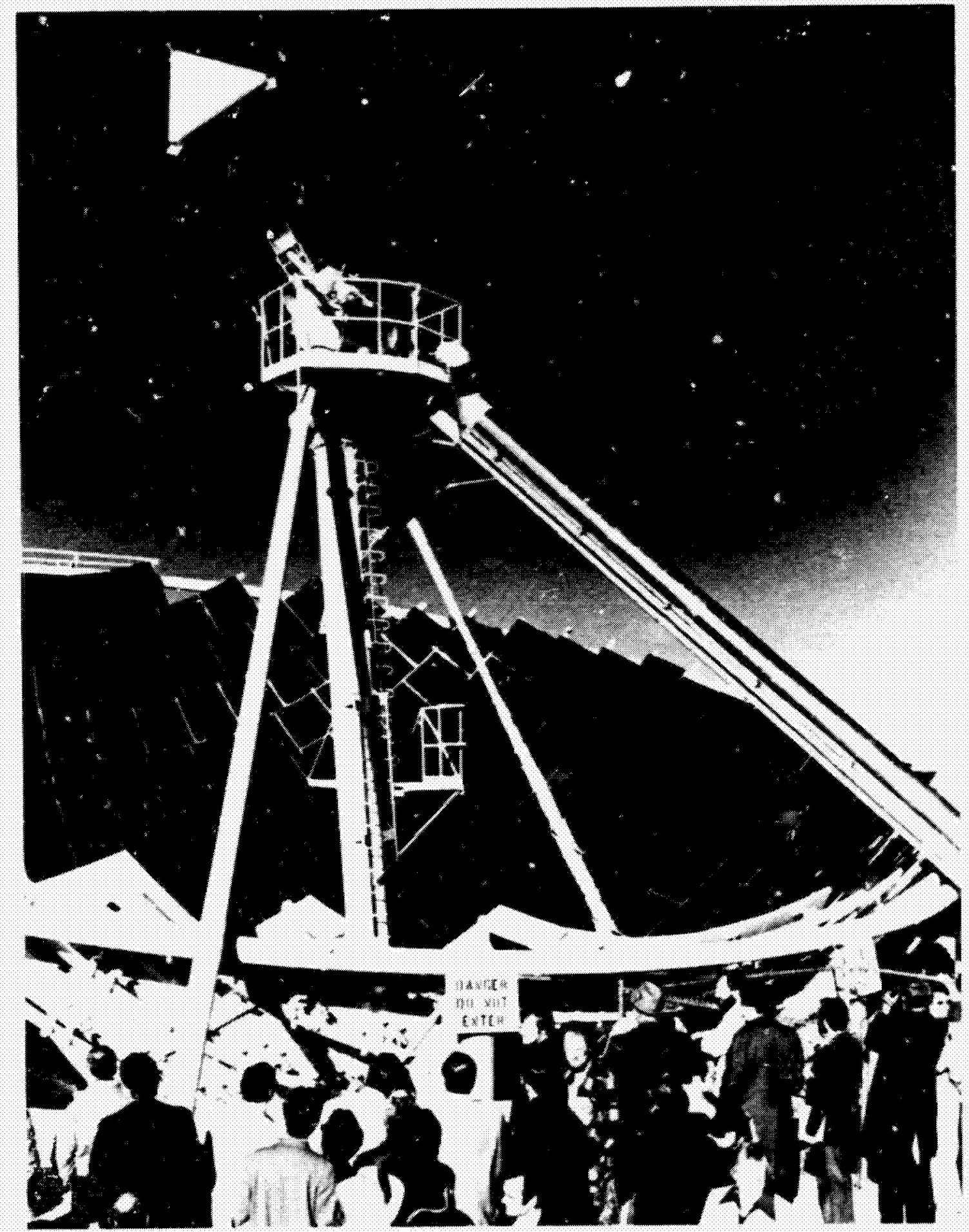

Figure 23. Crosbyton Concentrator: Fixed Spherical Bowl (Line focusing; movable receiver. Listed in Table 1 under designer, Texas Technical University.) 
ORIGINAL PAGE IS

OF POOR QUALITY

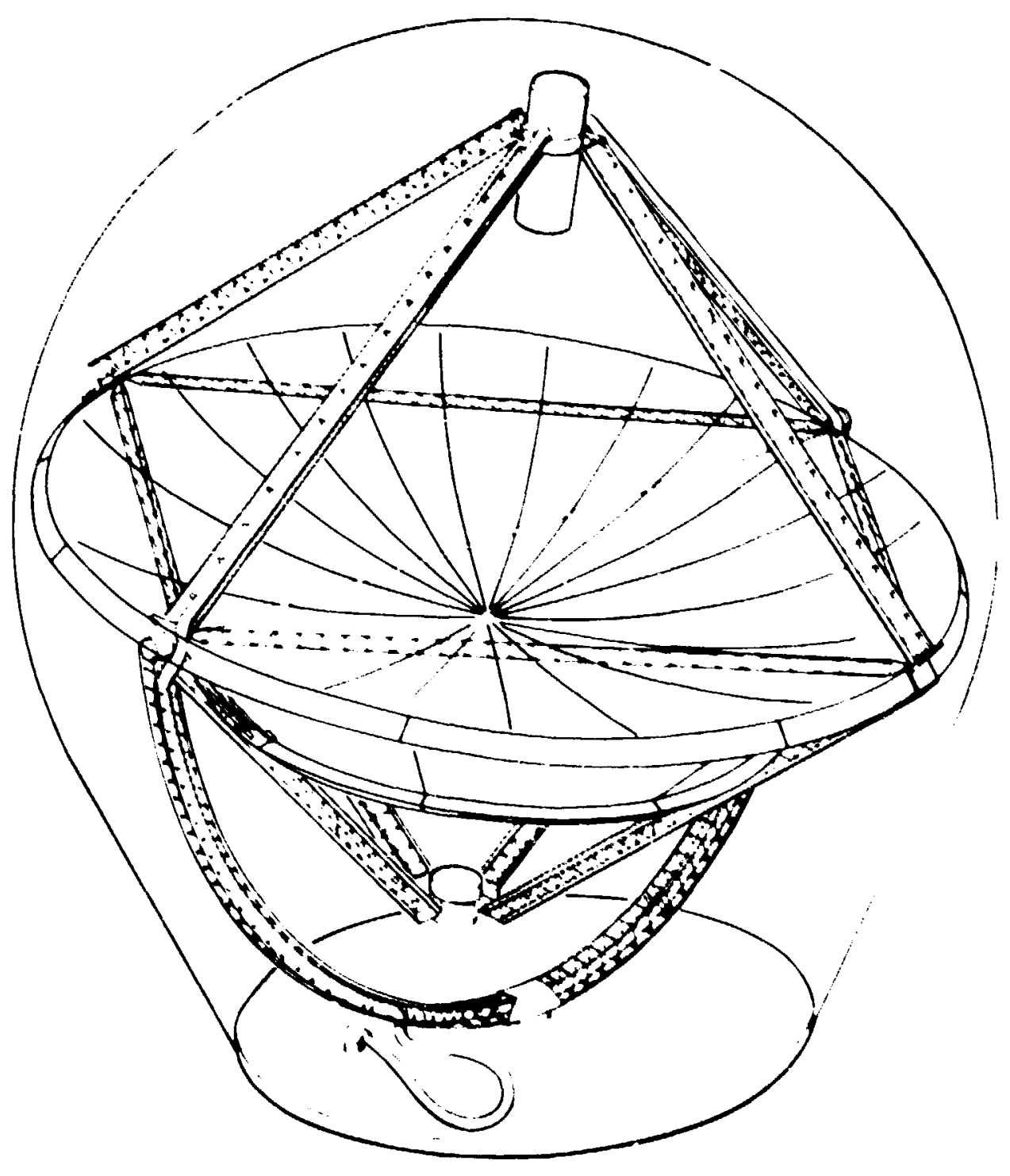

Figure 24. Boeing Enclosed Concentrator 
CRIGWNL PAGE

BLACK AND WHTE PHOTOGRAPH

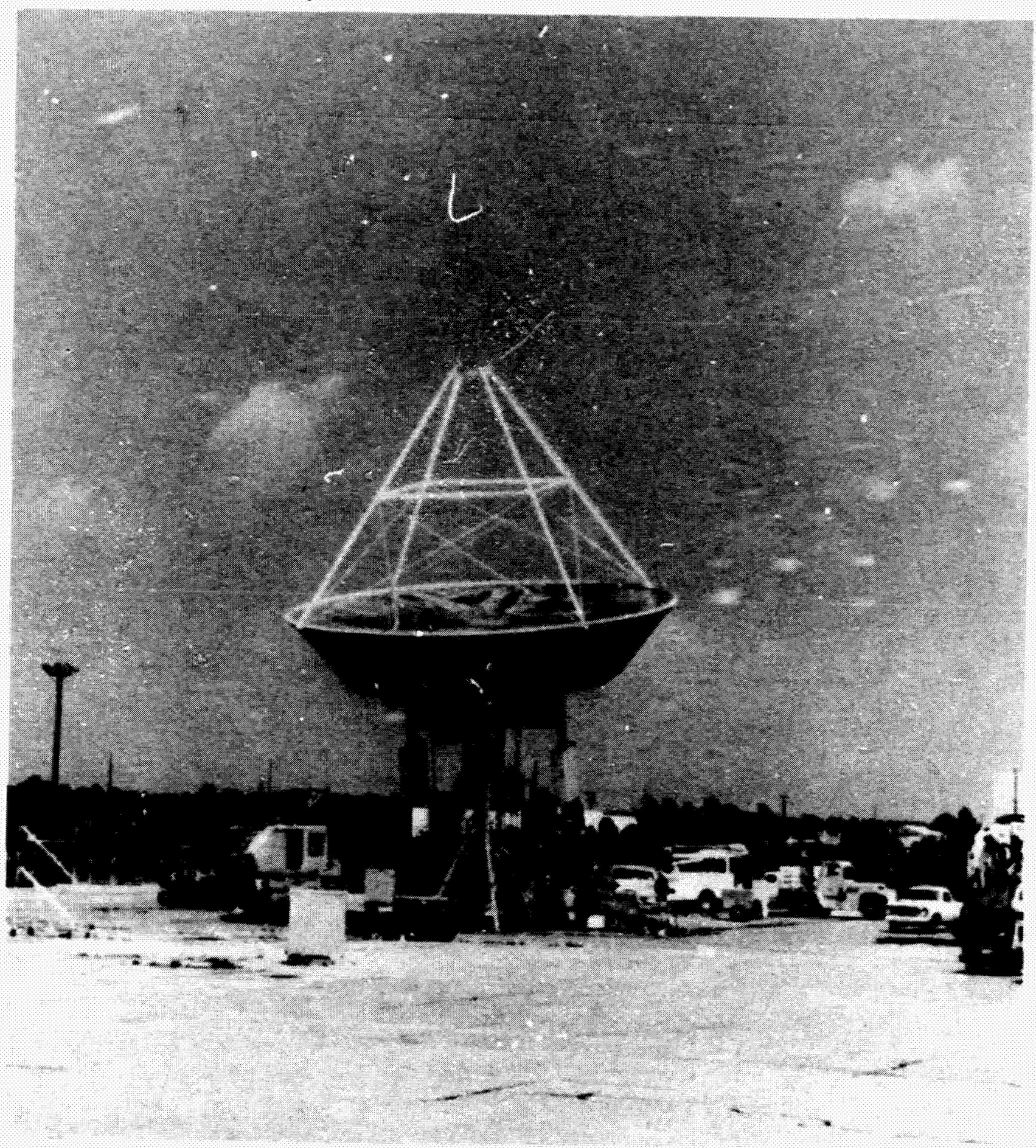

Figure 25. Transolar Concentrator 
UNGINAL PAGE

ELACK AND WHITE PHOTOGRAPH

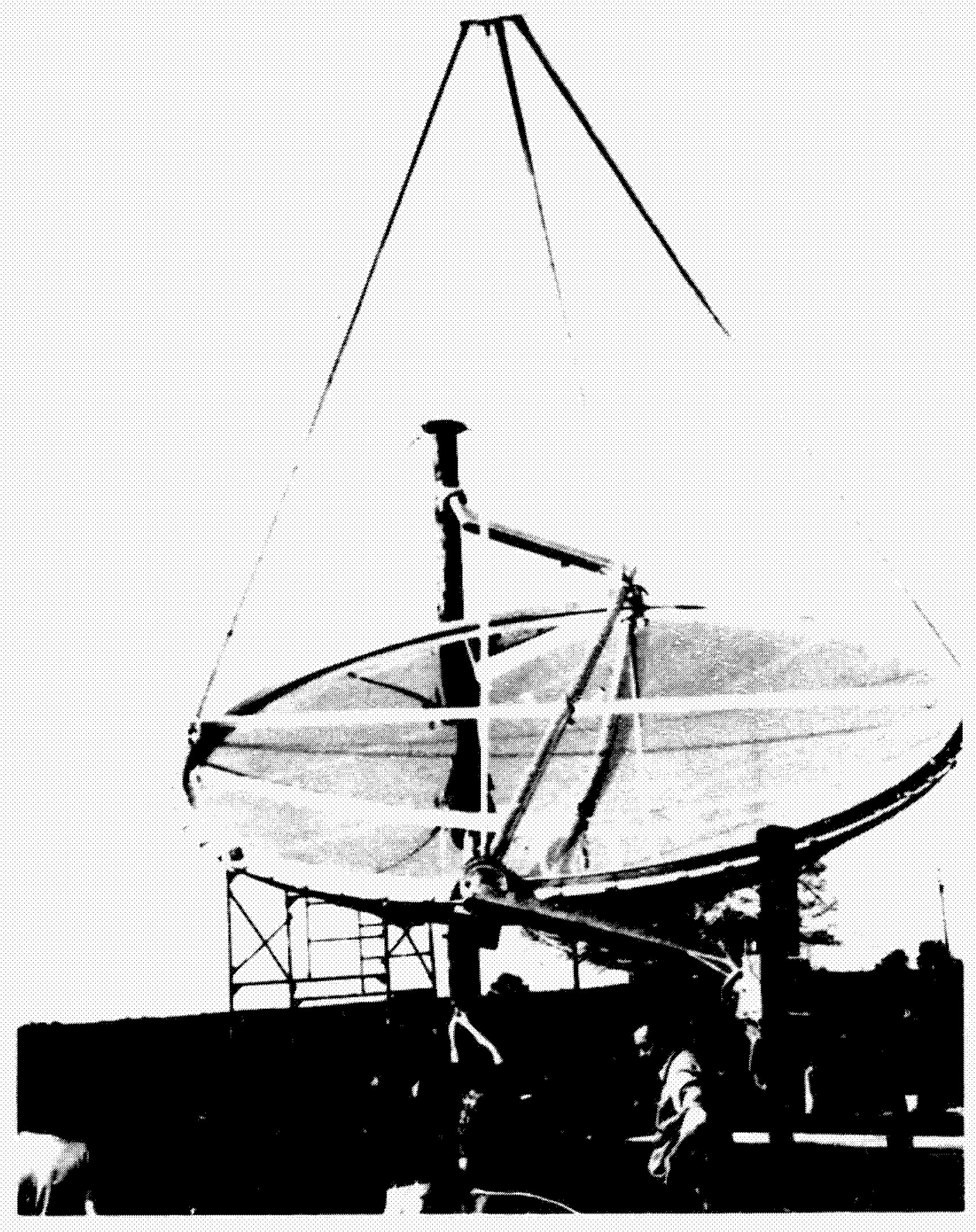

Figure 26. Summit Industries Concentrator 
ORIGINAL PAGE IS

OF POOR QUALITY

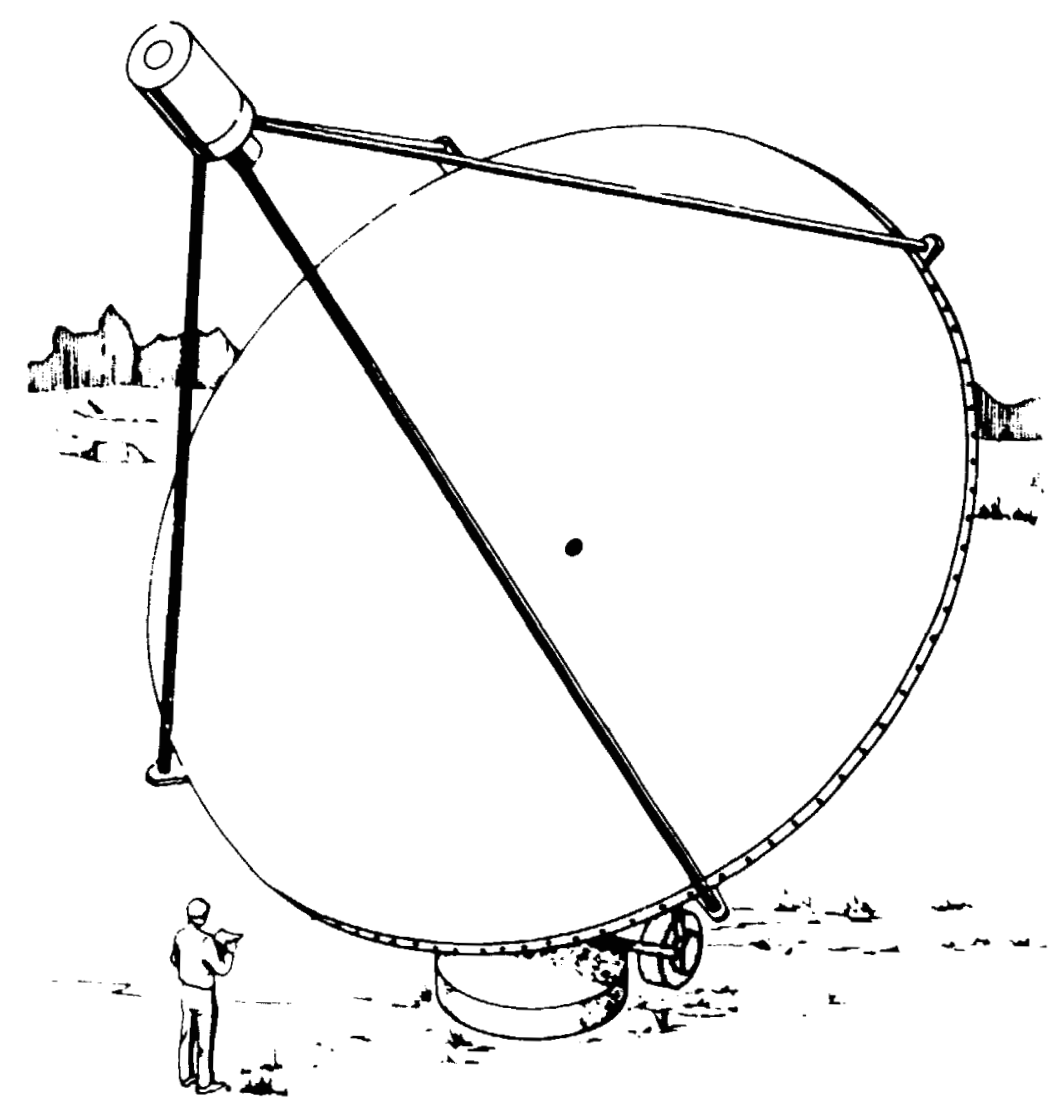

Figure 27. AaI Concentrator 
SECTION III

CONCENTRATOR PERFORMANCE AND COST

The desirability of low concentrator cost has been mentioned. Low-cost concentrators, however, must have performance adequate for the application. Therefore, both cost and performance must be considered.

\section{A. PERFORMANCE}

The performance of a solar concentrator may be expressed in terms of the flux distribution (absolute units) in its focal plane. This requires a graph or a table. It is often more convenient to express the performance as three numbers: (a) the optical efficiency and (b) the geometric concentration ratio at (c) a given intercept factor. The optical efficiency is the ratio of the solar energy delivered to the receiver to the direct solar energy incident on the concentrator aperture. The optical efficiency is equal to the product of the reflectance of the mirror (or transmittance of the iens), the shadowing and blocking factor due to sbjects in the optical path, and the intercept factor. The intercept factor is the ratio of the energy entering the receiver aperture to the concentrated energy reaching the focal plane. The geometric concentration ratio is the ratio of the concentrator aperture area to the receiver aperture area.

There is a trade-off between optical efficiency and geometric concentration ratio through the intercept factor. For a given concentrator, as the receiver aperture is increased, the intercept factor and therefore the optical efficiency also will increast. The increase in receiver aperture (decrease in geometric concentration ratio) will increase losses from the aperture by reradiation and convection. Usually intercept factors of 0.9 or higher are of interest; occasionaily, lower intercept factors may be optimum. Typical optical efficiencies are 0.8 to G.95. Lower optical efficiencies are sometimes acceptable; higher efficiencies are always desirable if not too costly.

The geometric concentration ratio needed t,o provide reasonable performance of the cullector (concentrator plus receiver) increases with the receiver temperature. At high temperatures, where reradiation bec mes very important, a small receiver aperture (high geometric concentration ratio) is especially desirable. As Figure 28 a indicates, a concentrator providing a low geometric concentration ratio may be quite satisfactory for low temperatur? use and unsuitable (very inefficient) for high temperatures. The need for high temperatures, and therefore high geometric concentration ratios, depends upon the application. If the solar energy system produces heat for industrial processing, the demands of the process will determine the required temerature. If the system produces mechanical or electrical power, the temperature must be high enough to provide adequate heat engine efficiency. Heat engine efficiency increases with increasing engine inlet temperature because of the Second Law of Thermodynamics. There is, therefore, a receiver temperature at which the system efficiency is a maximum (F1g. 28b). As the figure shows, the position of the maximum varies strongly with the geometric concentration ratio and also depends upon engine characteristics (Fig. 29). Engine selection will greatly influence the cholce of receiver temperature and, hence, the geometric concentration ratio needed. 


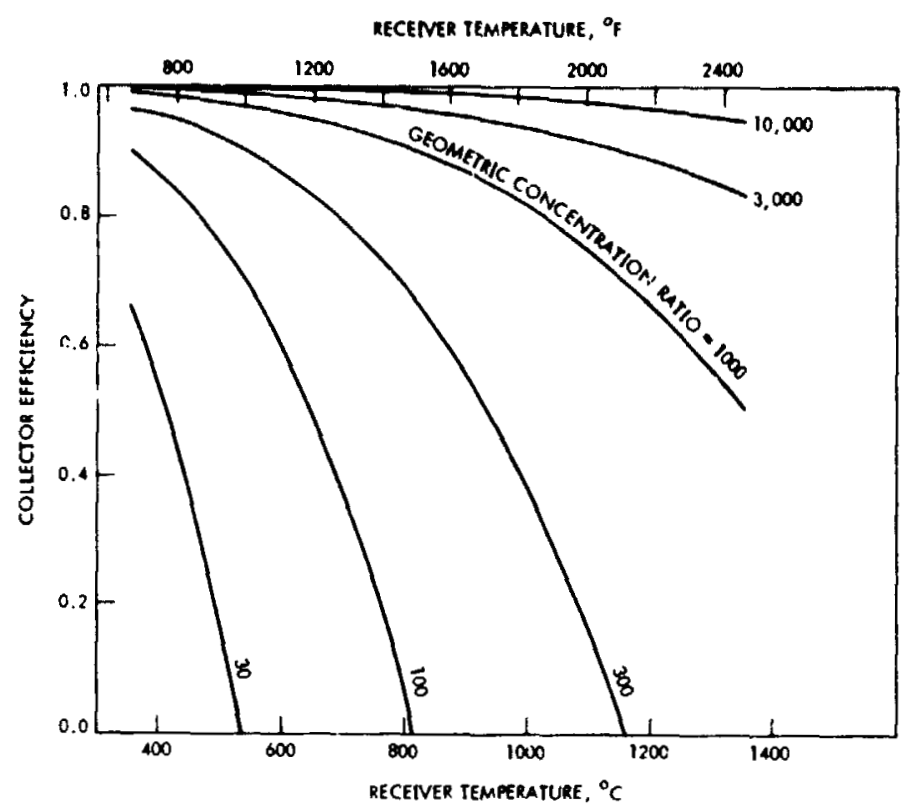

(a)

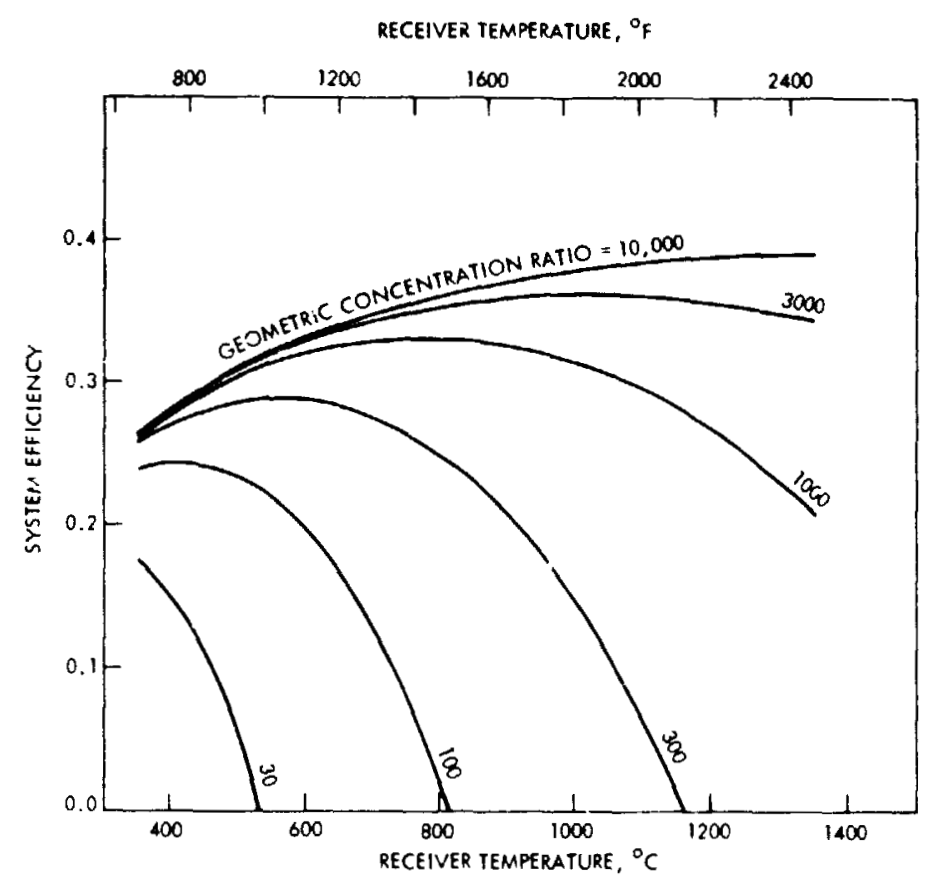

(b)

Figure 28. Effect of Geometric Concentration Ratio and Receiver Temperature on Collector and System Efficiency (Idealized System)

a) Collector (concentrator plus receiver) efficiency. Insolation (solar flu:) $=800 \mathrm{~W} / \mathrm{m}^{2}$

Focal ratio $=0.6$

Optical efficiency $=1.0$

Cavity receiver

Absorptivity $=$ emissivity $=1.0$

Receiver loss: only reradiation through aperture

b) System efficiency.

Engine inlet temperature $=$ receiver temperature

Dower conversion effectiveness (efficiency as

(raction of (arnot) $=0.5$

No other losses 


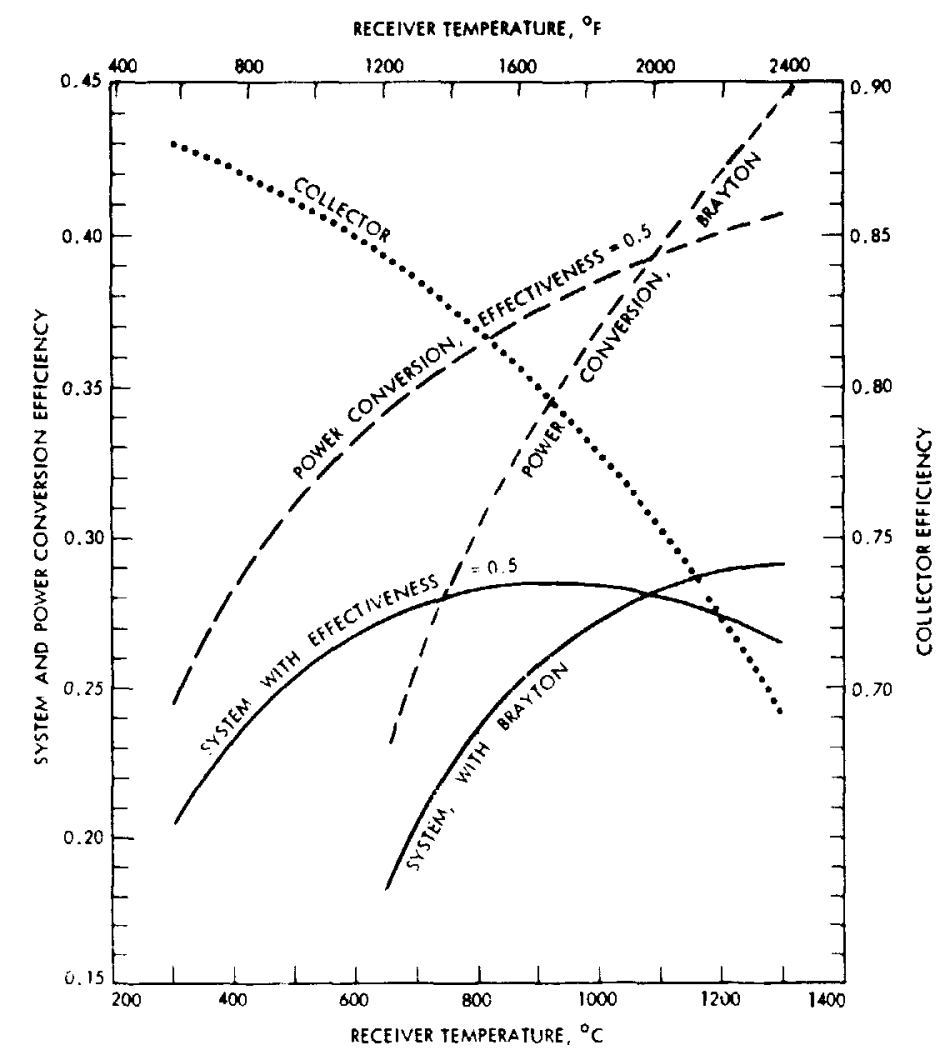

Figure 29. System Efficiency Versus Receiver Temperature with Engines of Differing Characteristics

Effectiveness (percent of Carnot efficiency) of Brayton engines rises with inlet temperature.

Effectiveness of Rankine and Stirling engines is approximately independent of inlet temperature.

Insolation (solar flux) $=800 \mathrm{~W} / \mathrm{m}^{2}$.

Focal ratio $=0.6$.

Reflectivity $=0.95$.

Blocking and shadowing factor $=0.967$.

Specularity $=0.5 \operatorname{mrad}(1 \sigma)$.

Slope error $=2.2 \mathrm{mrad}(1 \sigma)$.

Geometric concentration ratio optimized at each temperature (receiver aperture adjusted) using Aparisi approximation (Refs. 46-48) for flux distribution.

Cavity receiver. Effective absorptivity $=0.982$. Effective emissivity $=0.998$. Receiver convective + conductive heat transfer coefficient $=7, .6 \mathrm{~W} /{ }^{\circ} \mathrm{C} \cdot \mathrm{m}^{2}$ of aperture area. Temperature drop, receiver to engine $=20^{\circ} \mathrm{C}\left(36^{\circ} \mathrm{F}\right)$.

Brayton engine efficiencies per Ref. 45; efficiency of alternator + rectifier taken $=0.92$. A fixed effectiveness may represent the variation of power conversion efficiency versus temperature for Rankine and Stirling engines. The numerical value of the effectiveness, however, depends upon the particular engine. Power conversion effectiveness $=0.5$ is assumed here. Power processing efficiency $=0.95$. 
The geometric concentration ratio attainable at a given intercept factor principally depends upon the focal ratio (focal length/diameter), slope errors, specularity, and pointing error of the concentrator optical surface. With a paraboloidal roflector and a cavity receiver, the geometric concentration ratio at a fixed intercept factor is highest at a focal ratio of 0.5 to 0.6 ; longer and shoriar focal ratios lower the concentration ratio. Slope errors of the concenirator surface (deviations from the nominal shape) have a strong effect upon the attainable concentration: Figure 30 illustrates this for point-focusing paraboloids. Slope errors may be introduced during design, by manufacturing deviations, during shipping or installation, by structural or thermal deflections, and by distortion due to aging or weathering. Imperfect specularity nas an effect similar to that of slope errors, but half as great for the same angular spread of the mirror. Pointing errors tend to lower the geometric concentration ratio attainable at a given intercept factor by moving the solar image off the receiver aperture; in most tracking concentrators they are less limiting than are slope errors. Typical geometric concentration ratios for point-focusing solar thermal systems are 100 to 5000 .

\section{B. $\cos T$}

System studies indicate that the cost of concentrators generally will be the largest single cost element in solar thermal systems produced in quantity and hence will have a major effect upon the cost of the energy produced (Fig. 31; Ref 49). Therefore, concentrator costs must be considered carefully.

Many factors affect the cost of a concentrator. In mass production, the cost of materials is likely to be most important. Thus, there is much incentive to minimize the weight of materials and to use inexpensive materials. Tooling, direct and indirect labor, manufacturer's general and administrative expense, marketing and distribution costs, and profit contribute to the selling price. The cost of capital, tax provisions, etc., have significant effects. The user also must consider transportation, land, site preparation, foundation, and installation expenses. Foundation and installation work, involving field labor, can be especially expensive and needs to be minimized. There may be architect-engineer costs for design and supervision of site installation, and costs for construction management. Costs of permits and environmental impact statements may be included. After installation, there will be costs for cleaning, maintenance, and replacement of parts; these can be very significant in determining the lifetime cost. There also will be operating expenses.

When only a few concentrators are being produced, the relative significance of cost elements will be different than for quantity production. Design and development costs may have to be amortized, tooling costs may be very important, and fabrication labor costs may be high relative to material costs. A concentrator design intended for mass production, therefore, will probably need to be modified for economical production in limited quantities, and vice versa.

Concentrator costs are often expressed in $\$ / m^{2}$ of aperture area. In using such figures, it is important to identify the year to which the dollars refer -- 1980 dollars are not the same as 1975 dollars -- and whether the number represents manufacturer's cost, f.o.b. price, installed cost, cost with iffetime clearing and maintenance, etc. Further, it is not meaningful to compare concentrators on the basis of $\$ / \mathrm{m}^{2}$ unless their performance is the 


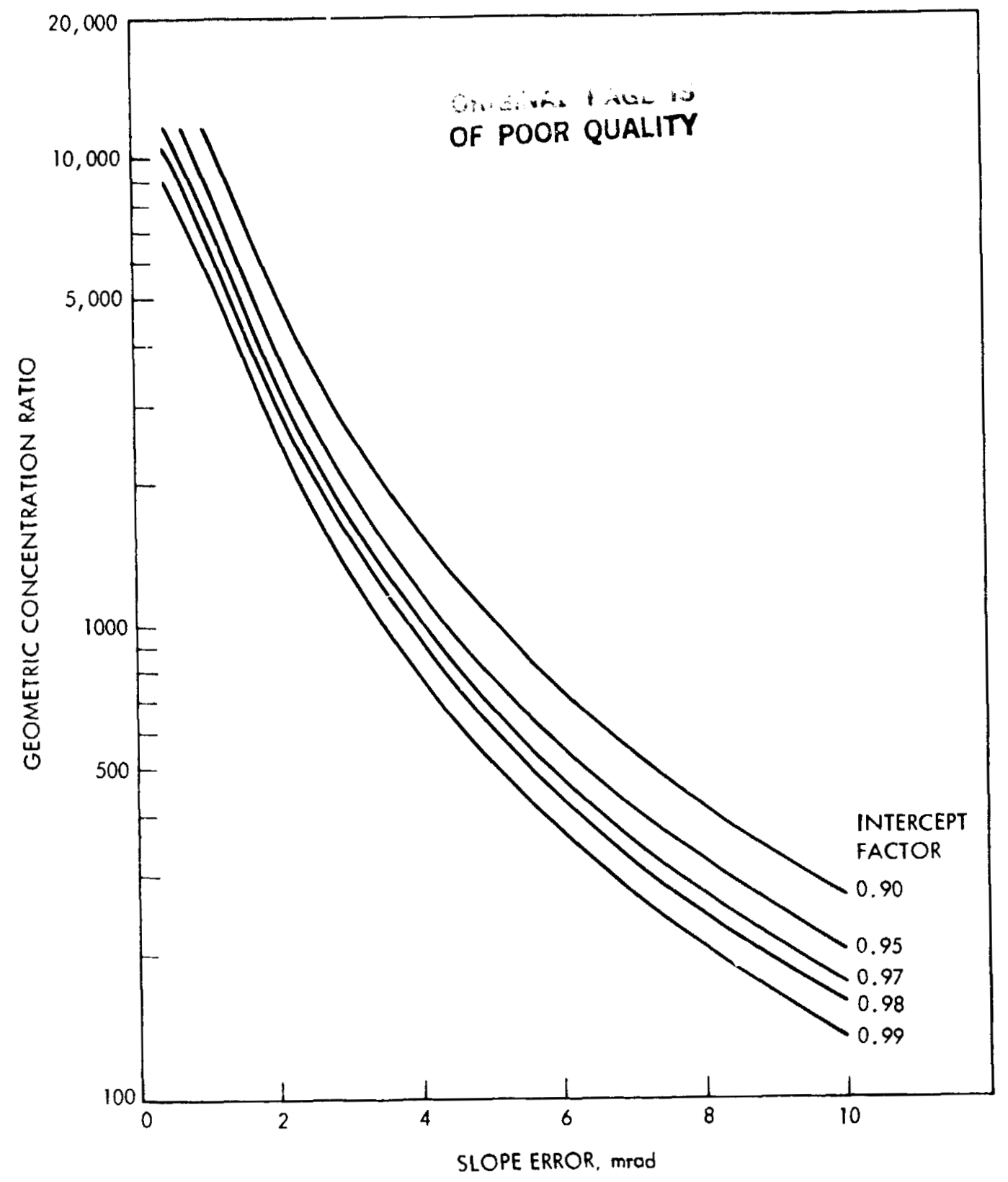

Figure 30. Geometric Concentration Ratio Attainable for Paraboloidal Mirror as a Function of Slope Error and Intercept Factor

Focal Ratio $=0.6$.

Angular standard deviation of sunlight taken as 2.3 mrad. Slope error is given as standard deviation, with specularity included in slope error. No pointing error.

Aparisi approximation (Refs. 46 through 48 ) used for flux distribution. 


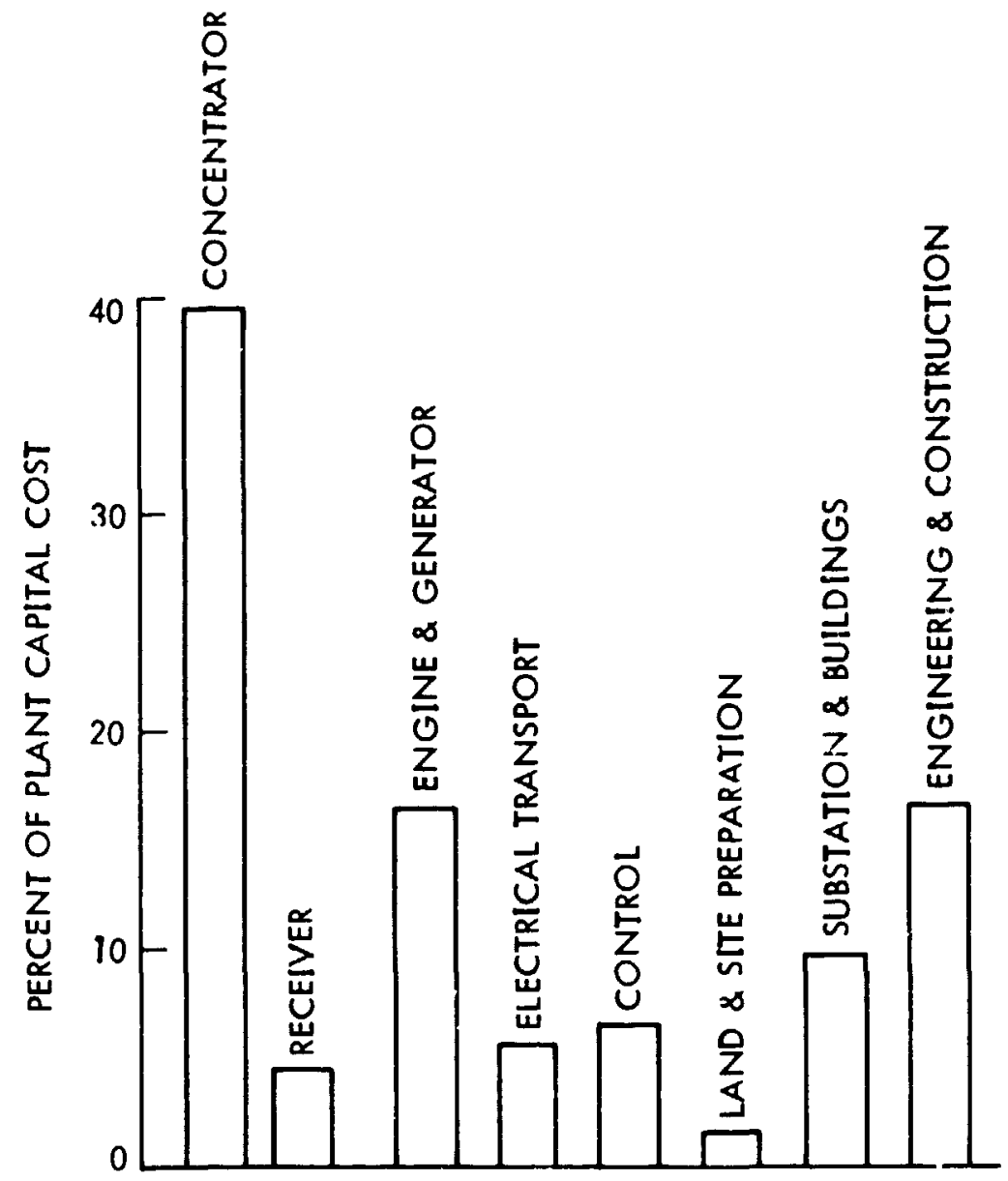

Figure 31. Distribution of Capital Costs for Solar Thermal Power Plant (Projected)

System type: dish-Brayton electric.

Production rate: 25,000 concentrator modules per year. Plant size: $5 \mathrm{MWe}$.

Based on data in Ref. 49. 
same. It is better to state $\$ / \mathrm{m}^{2}$ with accompanying values of geometric concentration ratio, intercept factor, ard optical efficiency, and even better to use a cost/performance value such as $\$ / \mathrm{kWt}-\mathrm{h}$ or $\$ / \mathrm{MBtu}$ for net thermal

energy into the receiver. ( $k W t-h$ stands for thermal $k W-h$.) Even this wethod requires that the recelver temperature also be speclfied, as well as the economic assumptions (interest and inflation rates, etc.).

A target of less than 100 mills/kWe-h (electrical kW-h) has been suggested for electricity produced by solar thermal electric systems for use in the mid-1990's, on the basis of both the price needed to meet competition from fuel-fired systems and the costs consioered possible to attain in mass production by that time (Ref. 50). This cost target is a levelized bus bar energy cost ( $\overline{\mathrm{BBEC}}$ ) in 1980 dollars; the corresponding "real levelized cost" $\left(\mathrm{BBEC}_{\mathrm{O}}\right.$ ) in constant ("real") dollars is 50 mills/kWe-h. ( $\overline{\mathrm{BBEC}}$ assumes that costs inflate, but that the electricity produced will be sold or valued at a constant mil: $\mathrm{s} / \mathrm{kW}-\mathrm{h}$ rate despite inflation. $\mathrm{BBEC}_{\mathrm{O}}$ assumes that the electricity will be sold or valued at a price which rises with the general level of infiation. For further explanation and assumptions used, see Reference 51.)

An examination of solar thermal power system costs suggests that an initial installed price of $\$ 90-150 / \mathrm{m}^{2}$ (in 1980 dollars) for the concentrator would be consistent with the electricity cost target, given the following conditions: a concentrator optical efficiency of 0.90 to 0.93 , a geometric concentration ratio of 2000 to 2500 at an intercept factor of 0.98 , and a lifetime of 30 years. Figure 32 indicates how the cost of electricity produced varies with the optical efficiency and concentrator cost. Figure 32 shows the effects of geometric concentration ratio on the cost of electricity produced. 
ORIGINAL PAGE IS

OF POOR QUALITY

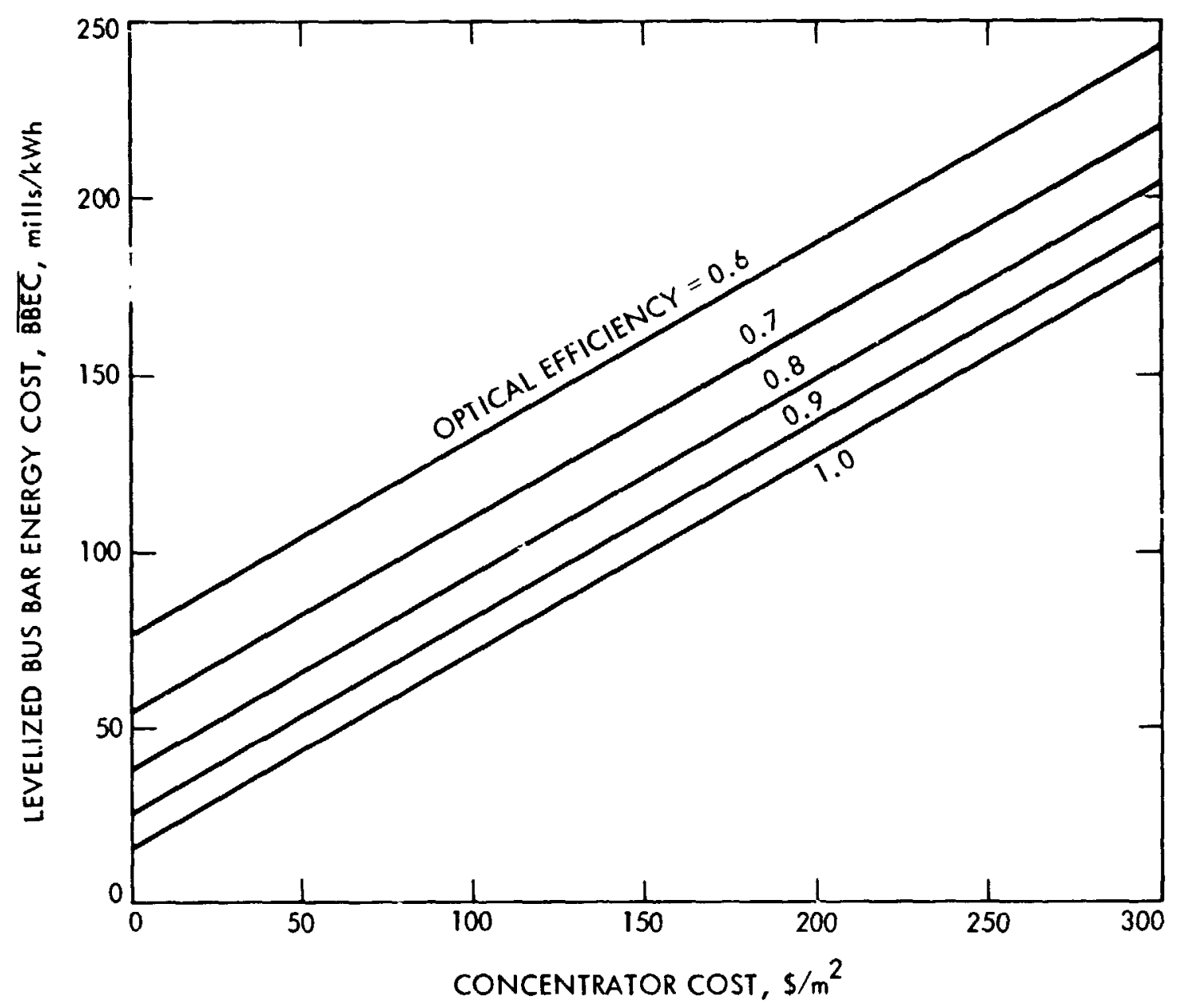

Figure 32. Effects of Concentrator Cost and Optical Efficiency Upon Cost of Electricity Produced (Projected)

Geometric concentration ratio $=2500$ at intercept factor $=0.98$.

Receiver temperature $=912^{\circ} \mathrm{C}\left(1675^{\circ} \mathrm{F}\right)$.

Power conversion efficiency $=0.342$ (Brayton ergine, directly-driven alternator).

Power processiraz efficiency $=0.95$.

Required concentrator area varies inversely with optical efficiency.

Influence coefficient relating electricity cost to concentrator cost based on Ref. 49. 
ORIGINAL PAGE IS

OF POOR QUALITY

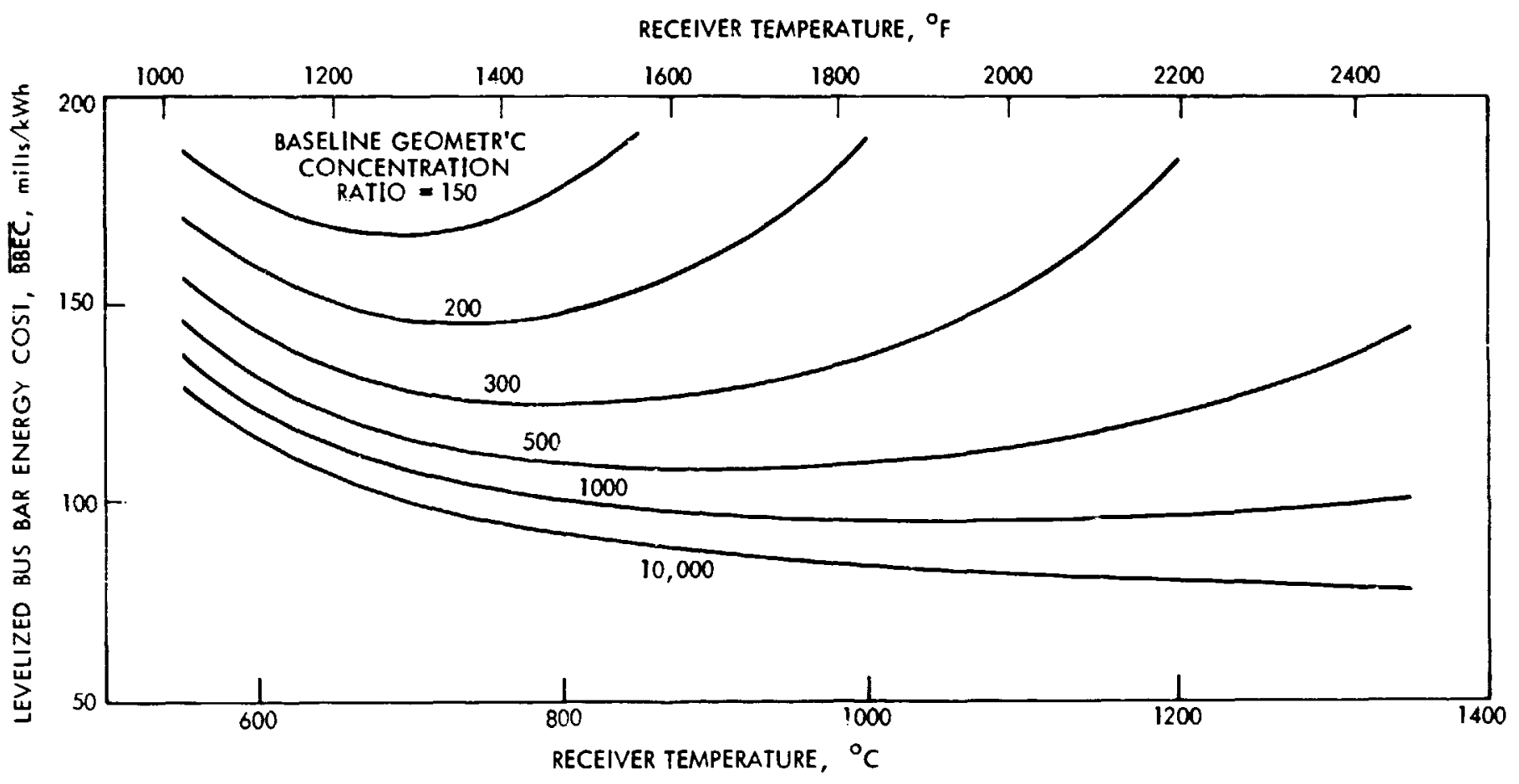

Figure 33. Effect of Geometric Concentration Ratio Upon Cost of Electricity Produced for Various Receiver Temperatures (Projected)

Concentrator cost $=\$ 90 / \mathrm{m}^{2}$.

Baseline optical efficiency $=0.90$.

Baseline geometric concentration ratio is the scometric concentration ratio at receiver temperature of $912^{\circ} \mathrm{C}\left(1675^{\circ} \mathrm{F}\right)$.

Concentrator slupe error such that baseline geometric concentration ratio is obtained at intercept fartor of 0.98 .

Receiver aperture adjusted to maximize collector efficiency for each temperature and slope error.

Engine efficiencies per Ref. 45. (Below $650^{\circ} \mathrm{C}$, variation with temperature per Ref. 52. Brayton engine, directly-driven alternator.) Alternator + rectifier efficiency $=0.92$.

Power processing efficiency $=0.95$.

Required concentrator area varies inversely with optical efficiency and power conversion efficiency.

Required size of power conversion subsystem varies inversely with power conversion efficiency.

Plant costs assumed to be otherwise independent of temperature.

Influence coefficients relating electricity cost to concentrator and receiver costs based on Ref. 49.

Costs in 1990 dollars. 



\title{
PRECEDING PAGE BLANX NOT FILMED
}

\author{
SECTION IV
}

TECHNOLOGY DEVELOPMENT

The state-of-the-art is illustrated by the concepts shown in Table 1 and Figures 1 through 27. To obtain concentrators with lower cost and good performance, effort is needed in the areas of concentrator concepts and designs, manufacturing and installation methods, and maintenance methods. Technology development and testing are also desirable. Work in these areas is discussed in the following paragraphs, as are the technology requirements needed in certain cases to guide this development.

\section{A. OPTICAL CONFIGURATIONS}

As mentioned above, a number of optical configurations have been identified as of possible interest, for point-focusing solar concentrators, and new configurations continue to be proposed. Some analysis of their optical performance has been done, but more is needed. (Some examples for non-paraboloids are References 2, 19, 41, and 53 through 56.) The quantity to be calculated is the flux distribution in the focal region, on an absolute scale, when the governing characteristics are var:ed parametrically. Slope errors and other properties of real optical components must be included among these characteristics.

\section{B. OPTICAL MATERIALS}

Improvements in the reflectance of solar mirrors provide an equivalent percent improvement in the performance and cost-effectiveness of concentrators. Durability of the reflecting layer can represent a major limitation to concentrator lifetime. Improvements in performance, cost, and lifetime, therefore, are needed.

Glass is the conventional material for the substrate or superstrate of mirrors, as well as for lenses. The use of polymeric optical materials for mirror superstrates and lenses may reduce concentrator cost. Development of polymer films and sheets with ti. op optical performance, high resistance to weather, and formability is needed. Transparent polymeric or inorganic coatings may provide means of making first-surface mirrors practical for concentrators. If this can be done, the possibilities of using reflective layers deposited on metal substrates also should be examined.

Better polymeric edge sealants and polymeric or inorganic backing materials are needed to increase the weather-resistance of second-surface glass mirrors.

\section{WIND LOADS AND AERODYNAMICS}

In most cases, aerodynamic wind loads are the major loads on concentrator struct-res. At present, the basic wind speed for concent, ator survival is usually specified as 90 or $100 \mathrm{mph}$ at a height of $30 \mathrm{ft}$ or $150 \mathrm{~km} / \mathrm{h}$ at $10 \mathrm{~m}$. 
The baslc wind speed for dish operation usually is specified as $50 \mathrm{~km} / \mathrm{h}$ (30 ol $40 \mathrm{mph}$ ) at the same height. Other values may be specified for stowing. Since the wind loads vary as the square of the speed, the exart choice of wind speed is important. The higher cost of a concentrator designed to withstand higher wind speeds must be traded against the higher risk of failure or the lower avallability of power and lower annual energy output if a lower wind speed is used for the dish design. This trade-off should consider the wind probabilities for various geographic areas and types of sites where the concentrators may be used. Height specification is also a factor: Should concentrators be designed to permit use on top of tall buildings where the wind speed is higher than near the ground?

The ANSI standard (Ref. 57) and nationally used building codes cover gust loads oy applying a multiplication factor to the loads prescribed for constant wind velocity. This standard may be inappropriate for dish concentrators because they tend to be much less rigid than buildings, and their dynamic response should be taken into account. To calculate this response, one must have as input the frequency spectrum of the wind turbulence and its variation with direction. Appropriate selection of these values, therefore, is necessary.

Several investigations have shown that for heliostats, enclosure domes, and flat photovoltaic panels, wind speeds and loads are aignificantly reduced by using arrays of these devices and by wind breaks (wind fences). Since wind loads are critical to dish concentrators, it is advantageous to take advantage of such array and fence effects to reduce triese loads. A careful examination of avallable data may lead to establishment of less stringent wind load requirements when wind fences are used around arrays.

A Iimited amount of work has been done on concentrator aerodynamics (RAf. 58); more work is needed. The shapes of actual concentrators will be design-specific and somewhat complex. Valuable information, however, could be obtained by examination of simplified concentrator shapes. These should not be confined to representations of parabololdai dishes, but should cover other geometrles such as Fresnel reflectors and lenses, enclosures, etc. The placement of the concentrators with respect to the ground plane and their size relative to the boundry layer thickness will be important parametric variables. Both computer-aideri analysis and wind tunnel testing appear appropriate.

\section{ENVIROMMENTAL REQUIREMENTS - PRECIPITATION, SAND, AND SEISMIC}

The expected amounts of snow, 1ce, and seismic activity vary widely from place to place. Geographic distributions of these quantities should be combined with estimates of the likely geographic distribution of point-focusing solar concentrators to establish requirements for loads due to snow, 1ce, and seismic activity. A consideration in determining these requirements will be the tolerable risk of failure. A simllar approach is needed for hail, a hazard to optical elements especially.

Another set of environmental requirements that needs to be better defined is that pertaining to wind-blown sand and dust, which can damage or dirty optical surfaces. The approprlate requirements with respect to particle size or mass distribution, velocity distribution, and variation with height above 
the eround are not clear and need to be determined, as well as, perhaps, such characteristics as particle shape, composition, and adhesive properties under various conditions.

\section{E. STRUCTURAL CONFIGURATIONS}

New structural configurations for concentrators may lead to significant reductions in concentrator costs. Analysis of the performance and costs of novel and more conventional types of concentrator structures is desirable. Such analysis shouid consider deflections produced by gravity, wind loads, and dirferential thermal expansion; these deflections will generally degrade optical performance. Dynamic effects arise frow wind gusts and drive mechanisms; these effects may be important in determining structural failure, optical performance, and stability and accuracy of the pointing control loops. Structural dynamics and their interactions with optics and controls, therefore, should be investigated.

\section{F. STRUCTURAL MATERIALS}

There is interest in the possibility of using polymeric materials and forest products (wood and, perhaps, paper) in concentrator structures to reduce costs. Dimensional stability and stability of mechanical properties of these materials under long-term exposure to weather are not adequately known and need to be determined more accurately.

\section{G. ENCLOSURES}

Enclosures of thin polymeric films offer a way to protect concentrators from the weather and thus alleviate effects of wind, snow, ice, hail, and ultraviolet exposure. This could lead to major reductions in concentrator cost if satisfactory enclosures can be developed. Enclosures may be supported by air pressure or by structure. Analytical and wind-tunnel data on enclosure response to wind loading are avallable (Ref. 59); field measurements also would be useful. Additional analytical and wind tunnel work could be done, including effects of interactions between enclosures and between wind fences and enclosures.

A variety of materials properties also need to be evaluated for enclosures. These include the following: the cost of the material and of enclosure fabrication and deployment; optical quality as affected by intrinsic materlal properties, by film fabrication and enclosure fabrication, and by the environment; the strength, toughness, flexibility, and density; the mechanical durability; the effects of long-term exposure to weather; the effects of elevated temperatures (arising, for example, from concentrated sunlight impingirg upon the enclosure); and soiling and cleaning. Opt lcal losses to be considered include those due to surface geometry, surface reflection, absorption, refractive index non-uniformities, bulk and surface scattering, and soil absorption and scattering. 
Important as it is for concentrators generally, cleaning and its associated costs (discussed in the next paragraphs) are even more important when an enclosure is used, since the surface of the enclosure will be considerably laiger than the optical surface of the concentrator itself.

\section{H. MA INTENANCE AND ClEANING}

Little work has been done on the development of maintenance techniques for point-focusing concentrators. For such components as the drive mechanism, experience in other applications is probably adequate. For the optical elements, effort to develop maintenance techniques appears worthwhile. Accumulation of air-borne particulates and aerosols on the optical surfaces causes undesirable absorption and scattering, adversely affecting performance. (Operating efficiency losses in excess of $30 \%$ have sometimes been experienced.) Natural cleaning (e.g., by rain) and thus the net accumulation are strongly material-dependent as well as site-dependent. Net accumulation is most serious for $30 \mathrm{ft}$ polymers and least serious for glass. An understanding of adhesion mechanisms should lead to development of more cost-effective cleaning methods. Considerations include mechanical damage to the surface by cleaning and possible effects of residual cleaning agents on material aging. It also should be possible to develop material systems (bulk materials, surface treatments, and coatings) which have reduced tenacity for soil or which are self-cleaning.

\section{TECHNOLOGY DEVELOPMENT UNDERWAY}

Work is currently underway on most of the technology mentioned above. Some of these efforts are directed primarily toward dish concentrators. Some are aimed primarily toward heliostats, parabolic trough (line-focusing) concentrators, photovoltaics or other types of equipment. Work in the materials area is being undertaken as part of a U.S. Department of Energy plan for development of solar energy materials. Much, however, remains to be done on almost all of the problems mentioned. 


\section{SECTION V}

FIELD TESTING

Most important in the development of point-focusing concentrator technolog $J$ is the field testing and evaluation of complete concentrators. Without such testing, development of concentrator technology, concentrator designs, and concentrator fabrication techniques will be severely handicapped. Preferably, concentrators should be tested with receivers or other focal-point equipment instrumented to record their performance. Tests should include evaluation of performance before and after exposure to several years of weather. Unfortunately, only a few point-focusing concentrators of current interest, have yet been field tested (Table 1). 



\section{SECTION VI}

\section{SUMMARY}

A wide variety of point-focusing concentrators have been proposed and are in various stages of conception, design, and development. They differ in optical configuration, in optical materials, in support structure for the optical element and the receiver, in mount, foundation, drive, and controls, and in the use of enclosures. A number of designs of current interest are summarized in Table 1 and illustrated in Figures 1 through 27.

Concentrator performance may be measured in terms of optical efficiency and geometric concentration ratio. Optical efficiency is the product of mirror reflectance, the shadowing/blocking factor, and the intercept factor. The geometric corsentration ratio attainable at a given intercept factor depends upon the optical slope errors and the specularity of the mirror. The geometric concentration ratio needed depends strongly upon the design temperature of the receiver, which in turn depends upon the application and on the subsystem selected for conversion of thermal to mechanical or electrical energy.

Concentrator costs are important in determining total system costs and the cost of energy produced. Material costs and foundation and installation work, including field labor, are significant contributors to concentrator costs. For some applications, a reasonable target for the installed price of concentrators produced in quantity appears to be $\$ 90$ to $150 / \mathrm{m}^{2}$ (in 1980 dollars), with an optical efficiency of 0.90 to 0.93 , a geometric concentration ratio of 2000 to 2500 at an intercept factor of 0.98 , and a concentrator lifetime of 30 years.

To permit development of such concentrators, advances are needed in concentrator concepts and design, in manufacturing and installation methods, and in associated technology. Areas for such technology advancement include evaluation of optical performance of various configurations, improvements in optical materials for concentrators, establishment of design wind speeds and wind loads, utilization of concentrator interactions and wind fences to decrease wind loads, establishment of better requirements for exposure to precipitation, sand, and seismic enviroriments, evaluation of concentrator structural configurations, evaluation of polymeric and forest-product structural materials for long-term concentrator use, more data on enclosure materials and structures, and improvements in cleaning and maintenance of optical surfaces. Field testing and evaluation of complete concentrators are critically needed.

PRECEDING PAGE BLANK NOT FILMED 



\title{
PRECEDING PAGE BLANK NOT FILMED
}

\author{
REFERENCES
}

1. Truscello, V. C., "The Parabolic Concentrating Collector," Solar Thermal Concentrating Collector Technology Symposium, Denver, CO, June 1978.

2. Poon, P., and Higgins, S., "Optical Performance of Several Point Focusing Solar Concentrators," 86th National Meeting, Am. Inst. Chem. Engineers, Houston, TX, April 1979.

3. Jaffe, L. D., "Low Cost Concentrator Overview," 3rd Semiannual Advanced Technology Meeting: A Review of Advanced Solar Thermal Power Systems, Long Beach, CA, JPL 5102-129, pp. 7i-78, June 1979.

4. Truscello, V. C., and Williams, A. N., "Heat and Electricity from the Sun Using Parabolic Dish Collector Systems," JPL, Pasadena, CA, September 1979.

5. Carley, W. J., "Progress in Point-Focusing Solar Concentrator Development at JPL," American Section/ISES Annual Meeting, Phoenix, AZ, June 1980.

6. Leibowitz, L. P., and Liu, T. M., "Parabolic Dish Solar Collectors for Industrial Process Heat Applications," JPL, Pasadena, CA, December 1980.

7. AAI Corporation, "Design of a Point Focusing Thin-Film Solar Concentrator. Task 1 Report,n ER-10,596 to JPL, Baltimore, MD, September 1980 .

8. Beveridge, B. (compiler), "Parabolic Dish Concentrator Designs and Concepts," JPL Publication 400-98, Pasadena, CA, December 1980.

9. Bedard, R., and Overly, P, "Low Cost Concentrator, " Parabolic Dish Solar Thermal Power Annual Program Review, Pasadena, CA, January 1981, DOE/JPL 1060-46, May 1981.

10. Bell, D. M., and Bedard, R. J., Jr., "Advanced Concentrator Panels," Parabolic Dish Solar Thermal Power Annual Program Review, Pasadena, CA, January 1981, DOE/JPL 1060-46, May 1981.

11. Bedard, R., Overly, P., and Bell, D., "Point-Focus Solar Concentrator Technology," American Section/ISES Annual Meeting, Philadelphia, PA, May 1981.

12. Bedard, R. J., Jr., Acurex Corporation, unpublished communication, April 1981.

13. Hashom, B. J., Advanco Corporation, unpublished communications, January 1981 and January 1982; also, Advanco Corporation and Rockwell International, unpublished comunications, June 1980.

14. Lasko, J. H., and Zimmerman, F. K., "Low Cost Point Focus Solar Concentrator. Phase 1 Final Report, " Contract 955209 with JPL, Boeing Engineering and Construction Company, Seattle, WA, March 1979.

15. Boeing Engineering and Construction Company, "A Conceptual Design Study of Folnt Focusing l'hin-Film Solar Concentretors. Task 1 Report," report to JPL, Seatt le, WA, September 1980. 
16. Chromie, E., San Diego, CA, unpublished communication, January 1981.

17. Goldberg, V. G., "Test Bed Concentrator (TBC)," Proceedings First Semiannual Distributed Receiver Systems Program Review, Lubbock, TX, January 1980, DOE/JPL-1060-33, pp. 35-39, April 1980.

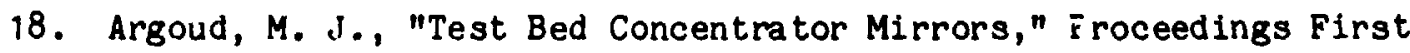
Semiannual Distributed receiver Systems Program Review, Lubbock, TX, January 1980, DOE/JPL-1060-33, pp. 41-46, April 1980.

19. E-Systems, Energy Technology Center, "Conceptual Design Study of Point Focusing Fresnel Lens Solar Concentrator, Conceptual Design Review," JPL Contract 955805, E-Systems ETC590380-149, November 1980.

20. Ford Aerospace and Communications Corporation, "Phase 1 of the First Solar Small Power System Experiment. Final Report," Ford Report J-6529 to JPL, Newport Beacin, CA, May 1979.

21. Kinoshita, G. S., "Development and Testing of the Shenandoah Collector," Parabolic Dish Solar Thermal Power Annual Program Review, Pasadena, CA, January 1981 , DOE/JPL 1060-46, May 1981.

22. Poche, A. J., "The Shenancioah Concentrator," Proceedings First Semiannual Distributed Receiver Systems Program Review, Lubbock, IX, January 1980, DOE/JPL-1060-33, pp. 59-61, April 1980.

23. Zimmerman, J., "General Electric Point Focus Solar Concentrator Status," Parabolic Dish Solar Thermal Power Annual Program Review, Pasadena, CA, January 1981, DOE/JPL 1060-46, May 1981.

24. Bank, H., JPL, unpublished communication, January 1981.

25. Zelinger, S. S., "The OMNIUM-G HTC-25 Tracking Concentrator," Proceedings First Semiannual Distributed Receiver Systems Program Review, Lubbock, TX, January 1980, DOE/JPL-1060-33, pp. 53-57, Apr 111980.

26. Owen, W., JPL, unpublished communication, January 1981.

27. Rogers, W., Borton, D., Rice, R., and Rogers, R., "Fresnel Concentrating Collector," Parabolic Dish Solar Thermal Power Annual Program Review, Pasadena, CA, January 1981, DOE/JPL 1060-46, May 1981.

28. Raytheon Co., Missile Systems Division, "Solar Collector Design and Fabrication Program. Final Report," BR-10394 to Sandia Laboratories, Bedford, MA, 1978.

29. Torkelson, L., Sandia Laborator les, unpublished communication, January 1981.

30. Wood, D., Solar Steam, Inc., unpublished comunication, January 1981.

31. Masterson, K., Solar Energy Research Inst1tute, unpublished communication, January 1981. 
32. Bradford, L., Summit Industries, unpublished communication, February 1981.

33. Sun Power Corporation, Letter Reports to JPL, JPL Contract 955564 , Fairfield, CT, 1979.

34. Reichert, J. D., "The Crosbyton Project," Proceedings F1rst Semiannual Distributed Receiver Systems Program Review, Lubbock, TX, January 1980, DOE/JPL-1060-33, April 1980.

35. Simpson, T. L., and Watson, K., Texas I'echnical University, unpublished communications, January 1981.

36. Brantley, L. W., Jr., "Pressure Stabilized Solar Crjlector (PSSC)," ERDA Conference on Concentrating Solar Collectors, Georgia Institute of Technology, Atlanta, GA, pp. 4-21 to 4-24, September 1977.

37. Grow, J., Transolar, Inc., unpublished communication, January 1981.

38. Price, J., NASA Marshall Space Flight Center, unpublished communication, January 1981.

39. Meinel, A. B., and Meinel, W. B., "Tensioned-Structure Faceted Fresnel Mirror (FFM) Point Focus Concentrator," Optical Sciences Center, University of Arizona and Arizona Scientific Research, Report 80-101 to JPL, Tucson, AZ, March 1980.

40. Winston, R., University of Chicago, unpublished communications, 1979-1981.

41. Poon, P. T. Y., and Higgins, S. N., "Optical Performance of a Fresnel-Type Concentrator with Truncated Paraboloidal Facets," Second International Hellosclence Institute Conference on Alternate Energy Sources, Palm Springs, CA, April 1978.

42. McDonnell Douglas Astronautics Company, "Novel Solar Collector Using a Large Circular Fresnel Lens Concentrator, Final Report," MDC G7452 to Sandia Laboratories, SAND 78-7023, Huntington Beach, CA, 1978.

43. Sanders Associates, "Parametric Analysis Review, High Temperature Solar Thermal Receiver," Report to JPL, Contract 955454, August 1979.

44. Jaffe, L. D., and Poon, P. T., "Secondary and Compound Concentrators for Distributed Point Focusing Solar Thermal Power Systems, " DOE/JPL-1060-43, April 15, 1981; also, Proceedings 16th Interscclety Energy Conversion Engineering Conference, 2, pp. 1752-1758, published by ASME, New York, NY, 1981 .

45. Heller, J., and Hyland, R. E., NASA Lewis Research Center, unpublished commun Ication, 1980 .

46. Umarov, G. Ya., "Problems of Solar Energy Generation, " Geliotekhnika 3, No. 5, pp. 32-51, 1967.

47. Rubanovich, I. M., "Objective Estimation of the Accuracy of the Reflecting Surface of the Parabololdal Concentrators of High-Temperature Solar Devices," Gellotekhnika 3, No. 6. pp. 26-33, 1967. 
48. Poluekiov, V. P., and Grilikhes, V. A., "Determining the Characteristics of the Radiation Field in the Focal Plane of Parabolic Solar Concentrators," Geliotekhnika -. No. 6, pp. 20-27, 1968.

49. Rosenberg, L., and Revere, W., "A Comparative Assessment of Solar Thermal Electric Power Plants in the 1-10 MWe Range," Jet Propulsion Laboratory, Publication 81-53, June 1981 ; also W. Revere, unpublished communication, 1981.

50. Habib-agahi, H., "Economic Cost Goals for Parabolic Dish Systems: Electric Applications," Jet Propulsion Laboratory, Internal Report 5105-21, March 1980.

51. Doane, J. W., O'Toole, R. P., Chamberlain, R. G., Bos, P. B., and Maycock, P. D., "The Cost of Energy from Utility-Owned Solar Electric Systems, A Required Revenue Methodology for ERDA/EPRI Evaluations," Jet Propulsion Laboratory, ERDA/JPL 1012-76/3, June 1976.

52. Garrett Corporacion, "Power from the Sun - Now," Torranze, CA, November 1979.

53. Unarov, G. Ya., and Alavutdinov, Dzh. N., "Investigation of Two-Mirror Systems Consisting of a Paraboloidal Mirror and an Inflated-Film Reflector," Geliotekhnika 4, No. 3, pp. 62-66, 1968.

54. Baranov, V. K., "Parabolotoric Focone as Secondary Solar Energy Concentrator," Geliotekhnika 13, No. 5, pp. 18-25, 1977.

55. Bass, A. H., Ir., Schrenk, G. L., Poon, P. T. Y., and Higgins, S. N., "Optical Analysis of Cassegrainian Concentrator Systems," 1979 International Congress, International Solar Energy Society, Atlanta, GA, May 1979.

56. Winston, R., and Welford, W. T., "Design of Non-Imaging Concentrators as Second Stages in Tandem with Image-Forming First Stage Concentrators," Applied Optics 19, pp. 347-351, 1980.

57. American National Standards Institute, "Building Code Requirements for Minimum Design Loads in Buildings and Other Structures," ANSI A58.1-1972, New York, NY, 1972.

58. Roschke, E. J., "Wind Loading on Solar Concentrators: Some General Considerations," Jet Propulsion Laboratory, Pasadena, CA, July 1980.

59. Houser, J., "Wind Tunnel Investigation of Air Loads on Heliostat Enclosures, University of Washington, UWAL-1196," Boeing D180-20542-1, Seattle, WA, 1977. 